\title{
VENEER-BASED TIMBER CIRCULAR HOLLOW SECTION BEAMS: BEHAVIOUR, MODELLING AND DESIGN
}

\author{
Benoit P. Gilbert ${ }^{(1)}$, Daniel Dias-da-Costa ${ }^{(2)}$, Arthur Lebée $^{(3)}$, Gilles Foret ${ }^{(3)}$ \\ (1) School of Engineering and Built Environment, Griffith University, Australia \\ (2) School of Civil Engineering, The University of Sydney, Australia \\ ${ }^{(3)}$ Navier laboratory, Ecole des Ponts, Université Gustave Eiffel, CNRS, Marne-la-Vallée, France \\ Corresponding author: b.gilbert@ griffith.edu.au
}

\begin{abstract}
Various forms of timber hollow structural profiles have either been proposed in the literature or are already commercially available. Tests performed on Circular Hollow Section (CHS) beams showed failure modes not usually encountered in timber structures. For relatively thin-walled profiles, a sudden failure in the compression zone, with the opening of the cross-section, was observed. To confidently use and market CHS timber products, design rules considering all possible failure modes must be developed. This paper presents a Finite Element (FE) model of CHS timber beams which captures all experimentally observed failure modes. Cohesive zone elements were used to model the quasi-brittle failure modes of the timber material. The model was validated against ten experimental tests performed on CHS of three different cross-sectional slenderness and manufactured from juvenile hardwood Gympie messmate (Eucalyptus cloeziana) rotary peeled veneers. The model was found to accurately capture the measured structural behaviour and resulted in an average experimental-to-predicted bending capacity ratio of 1.02 . The model was also used to explain the mechanisms leading to the sudden compressive failure mode. A parametric study was finally performed on $72 \mathrm{CHS}$ beams of different cross-sectional slenderness. Results showed a strong correlation between the cross-sectional slenderness ratio and section capacity. Design rules are proposed and discussed.
\end{abstract}

KEYWORDS: Timber Circular Hollow Sections, Buckling, Design rules, Juvenile hardwood veneers. 


\section{INTRODUCTION}

Hollow timber structural elements, either manufactured from boards or veneers, have been proposed in the literature [1-13] and some products are commercially available [14, 15]. These products have efficient cross-sectional shapes, are lighter than conventional plain timber elements and can be manufactured in sizes currently not available in sawn timber. Experimental investigations showed that they have the stiffness and strength required to be used, for instance, as structural elements $[1,2]$ and temporary anchor nails $[12,16,17]$. However, tests performed on Circular Hollow Sections (CHS) manufactured from either juvenile hardwood plantation veneers [1, 2] or moulded from beech boards [13], showed that the cross-section in compression could fracture and open. This failure mode linked to the hollowness of the cross-section is not encountered in plain timber structures commonly used in constructions. The phenomena leading to this failure mode have not yet been fully explained. Moreover, to confidently use and market CHS timber products, design rules considering all failure modes must be developed. For this purpose, this paper describes a Finite Element (FE) model of CHS timber beams that aims at capturing all experimentally observed failure modes. The model was validated against ten experimental tests performed on CHS timber beams of three different cross-sectional slenderness and was then used to explain the experimentally observed compressive sudden failure mode. Finally, the results from a parametric study on 72 CHS beams of different cross-sectional slenderness are presented and design rules based on the parametric study are proposed and discussed.

\section{REFERENCE TESTS}

This section introduces the experimental tests which were used to validate the FE model in this paper. The tests were performed in [2] on four $145 \mathrm{~mm} \times 15 \mathrm{~mm}$, and in [1] on three slender $167 \mathrm{~mm}$ $\times 12.5 \mathrm{~mm}$ and three compact $167 \mathrm{~mm} \times 25 \mathrm{~mm}$ CHS timber beams, all specimens subjected to a constant bending moment. The sections were manufactured from juvenile hardwood plantation Gympie messmate (Eucalyptus cloeziana) rotary peeled veneers and aimed at finding a high-value market 
for this under-utilised resource. Nominal $2.5 \mathrm{~mm}$ thick veneers were used in the manufacturing process and all were orientated along the longitudinal axis of the sections. A CHS beam was composed of two half-sections which were manufactured from different veneer sheets to fit the research purpose in $[1,2]$ and be consistent with what would be expected in industrial applications. The half-sections were butt-jointed together using structural epoxy resin, as shown in Figure 1 (a), and the butt joints were positioned at the neutral axis of the cross-sections during the bending tests. Figure 1 (b) shows a photo of manufactured CHS timber beams.

For all bending tests, the ends of the sections were rigidly connected to a test rig which applied the constant bending to the sections over a span $L$, given in Table 1 . For all tests, the curvature of the beams was recorded with three Linear Variable Displacement Transducers (LVDT) positioned at the extreme fibre in tension. Additionally, strain gauges recorded the longitudinal strain of the $167 \mathrm{~mm}$ diameter cross-sections at mid-span and at both tensile and compressive extreme fibres. The experimental bending test set-up is fully detailed in $[1,2]$ and the reader is kindly invited to refer to these papers for more information.

The material compressive $f_{c, L}$ or tensile $f_{t, L}$ strengths parallel to the grain of each half-section were measured from flat panels manufactured from the exact same veneer sheets as the half-sections. The Modulus of Elasticity (MOE) parallel to the grain $E_{L}$ of each half-section was obtained either by measuring the dynamic MOE of each veneer sheet using a non-destructive acoustic method [18, 19] or by using an extensometer during material testing. The measured material properties, thickness $t$ of the flat panels and diameter of the sections are summarised in Table 1. The full details on the manufacturing process and tests performed can be found in $[1,2]$.

Different failure modes were observed in the experimental tests. A compressive sudden failure mode occurred in some of the more slender sections, with the sections fracturing and opening, as shown in Figure 2 (a). Tensile failure, as typically encountered in timber beams, was also observed, as shown in Figure 2 (b). In some cases, failure developed at the rigid connections between the test 
rig and the section. The bending moments at which this failure occurred, therefore, represent lower bounds of the actual capacity of the tested sections. Nevertheless, those moments were shown to be of similar magnitude to the tensile failure capacities [2] and are taken herein as the tensile capacities. For comparison to the numerical model, this failure mode can therefore be regarded as tensile failure. Table 2 summarises the experimental moment capacities $M_{b_{-} \text {exp }}$, bending stiffness $E_{L} I_{-}$exp and failure modes. $E_{L} I_{-}$exp reported in Table 2 was calculated in $[1,2]$ by performing a linear regression on the linear part of the moment-curvature curves.

\section{FINITE ELEMENT MODEL}

\subsection{General}

The model of the CHS beams was built using the FE software Abaqus [20]. At the exception of Hartig et. al [21], the few attempts made in the literature to model the behaviour of hollow timber sections did not aim at fully capturing the fracture of the timber observed in Figure 2, see [4, 13] for instance, as the compressive sudden failure mode was not always observed. In Hartig et. al [21], continuous damage mechanics [22-26] was employed to model a vehicle impact on moulded wooden tubes. The model predicted well both the observed failure modes, and the acceleration and velocity versus time relationships of the vehicle after impact. The stress developing in the sections and the section capacity (impact force), however, were not numerically verified.

\subsection{Material definition}

\subsubsection{Elastic properties}

An orthotropic material was used to model the timber with the assumption that the properties in the radial and tangential directions, i.e. perpendicular to the grain, were equal. Evidence from the tests performed in [27] showed that for three hardwood species, including Gympie messmate, the dynamic MOE parallel to the grain of the veneer sheets is typically $5 \%$ to $15 \%$ lower than the static MOE of a Laminated Veneer Lumber (LVL) manufactured from the same sheets. Therefore, when validating the model, the MOE parallel to grain $E_{L}$ of each half-section was taken as 1.10 times the 
average measured dynamic MOE of the veneer sheets reported in Table 1 for the $167 \mathrm{~mm}$ diameter CHS. Note that an average difference of $12 \%$ was found for Gympie messmate in [27] between the dynamic MOE of the veneers and the static MOE of the LVL. The aforementioned coefficient of 1.10 was chosen for simplicity and to consider the variability in the measured difference. This value was found to satisfactory model the bending stiffness of the tested sections, as developed later in Section 4.3.1. For the $145 \mathrm{~mm}$ diameter CHS, $E_{L}$ was taken as the measured static MOE reported in Table 1. Other properties were taken from the literature, either for Gympie messmate (when available) or for hardwood species of similar density. Specifically, the MOE in the radial $E_{R}$ and tangential $E_{T}$ directions, and the shear modulus in the longitudinal-radial $G_{L R}$ and longitudinal-tangential $G_{L T}$ planes were taken as the typical values encountered for juvenile Gympie messmate [28]. Note that these values were shown to be uncorrelated to $E_{L}$ [28] and were herein assumed as constants. The shear modulus in the radial-tangential $G_{R T}$ plane and the Poisson ratios $\gamma_{L R}, \gamma_{L T}, \gamma_{R T}$ were taken for species of similar density in [29]. These values were also considered as constants. Table 3 summarises all elastic properties used in the model validation.

\subsubsection{Plasticity}

The ductile failure modes in compression parallel and perpendicular to the grain were captured using a modified elastic-perfectly plastic anisotropic Hill yield criterion [20], as:

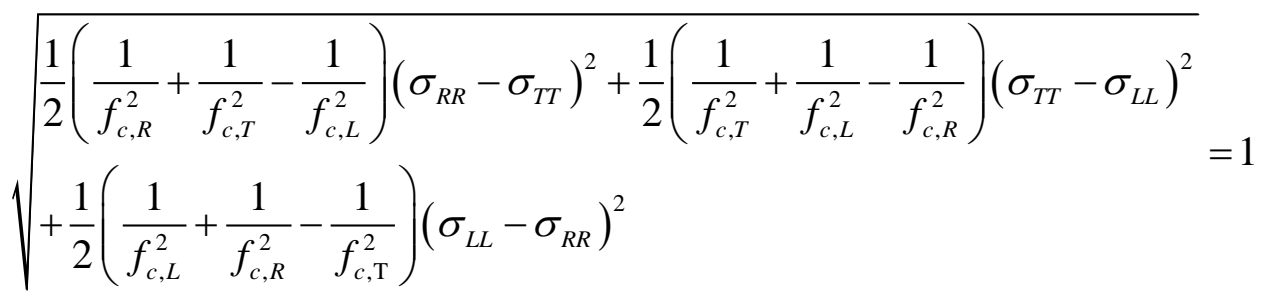

where $f_{c, R}$ and $f_{c, T}$ are the radial and tangential compressive strengths, respectively, and $\sigma_{L L}, \sigma_{R R}$ and $\sigma_{T T}$ are the longitudinal, radial and tangential stresses, respectively. While the Hill yield criteria is deviatoric, it is commonly used for the plasticity of wood [30-32]. Plasticity was only considered for the half-section in compression and the material in the half-section in tension was considered to remain elastic as the shift of the neutral axis resulting from plasticity developing in compression is not 
large enough for the plastification to extend past the butt joint. Tensile failure was inputted in the half-section in tension as developed in the following sub-section. The compressive strength parallel to the grain $f_{c, L}$ of each half-section reported in Table 1 was used to validate the model. The compressive strengths perpendicular to the grain $f_{c, R}$ and $f_{c, T}$ were obtained from the $1 \%$ strain offset [33] on five compressive tests performed as part of this paper on nominal $80 \mathrm{~mm}$ long $\times 45 \mathrm{~mm}$ wide samples. The samples were cut from five different flat panels of the $25 \mathrm{~mm}$ thick cross-sections and tested in a $500 \mathrm{kN}$ MTS universal testing machine to reach failure in 3-5 mins. Table 4 summarises the compressive strength values used when validating the model.

\subsubsection{Fracture}

A cohesive zone model (CZM) was used to model the quasi-brittle tensile and shear failure modes of the timber material [30, 34-37] based on eight-node COH3D8 cohesive elements [20] for this purpose. To capture the rupture developing in the compressive zone (Figure 2 (a)), cohesive elements were included through the thickness and along the longitudinal axis of the section - see Figure 3. Please note that the number and location of these elements are discussed in Section 4.2. Also note that while fracture near the glue line between two half-sections was experimentally observed (Figure 2 (a)), the fracture always developed in the timber and not in the glue line. Therefore, crack paths modelled near the glue line in Section 4.2 correspond to cracks developing in the timber. In addition, to model the tensile failure mode (Figure 2 (b)), a crack path was modelled with cohesive elements in the half-section in tension, as shown in Figure 3. This crack path was positioned $80 \mathrm{~mm}$ from the section end to avoid the tensile stress to be influenced by buckling potentially developing at the middle of the section and boundary conditions.

The maximum nominal stress criterion, with stresses extrapolated to the crack tip [20], was used for damage initiation in reference to the local reference system defined by the normal $(n)$ and tangential $(s, t)$ directions to the crack path as:

$$
\max \left(\frac{\left\langle\sigma_{n}\right\rangle}{f_{n}} ; \frac{\sigma_{s}}{f_{s}} ; \frac{\sigma_{t}}{f_{t}}\right)=1
$$


where $<>$ are the Macaulay brackets, $\sigma_{n}$ is the stress normal to the crack path, $\sigma_{s}$ and $\sigma_{t}$ are the first and second absolute shear stresses along the crack path, respectively, $f_{n}$ is the tensile strength normal to the crack path, and $f_{s}$ and $f_{t}$ are the first and second shear strengths along the crack path, respectively. The values of $f_{n}, f_{s}$ and $f_{t}$ depend on the orientation of the crack path. For the paths modelled in the half-section in compression (see Figure 3), $n$ is the tangential direction, and $\mathrm{s}$ an $t$ are the radialtangential (rolling) and longitudinal-radial planes, respectively. For the crack modelled in the halfsection in tension (see Figure 3), $n$ is the longitudinal direction, and $\mathrm{s}$ an $t$ are the longitudinal-radial and longitudinal-tangential planes, respectively.

When validating the model, the tensile strength parallel to the grain $f_{t, L}$ reported in Table 1 was taken for each half-section. The tensile strengths in the radial $f_{t, R}$ and tangential $f_{t, T}$ directions were derived as part of this study from tensile tests performed on five samples following the test methodology described in the ASTM D143-14 [38], but adapted to LVL [39, 40]. The samples were cut from the same flat panels which were used to measure $f_{c, R}$ and $f_{c, T}$ (Section 3.2.2) and tested in a $30 \mathrm{kN}$ Instron universal testing machine. The shear strengths in the longitudinal-radial $f_{s, L R}$ and longitudinaltangential $f_{s, L T}$ planes were taken as the median value measured for the $145 \mathrm{~mm}$ diameter CHS in [2]. The rolling shear strength $f_{s, R T}$ was taken as the $50^{\text {th }}$ percentile value measured in [28] on the same resources used in manufacturing the CHS. Table 4 summarises all tensile and shear strength values used.

A mixed mode damage evolution based on energy and linear softening were considered. The same fracture criterion previously used for timber in [30] was defined,

$$
\frac{G_{n}}{G_{n}^{c}}+\frac{G_{s}}{G_{s}^{c}}+\frac{G_{t}}{G_{t}^{c}}=1
$$

where $G_{n}, G_{s}$ and $G_{t}$ denote the work done in the elements in the normal direction to the crack path, and in the first and second shear directions, respectively, and $G_{n}^{c}, G_{s}^{c}$ and $G_{t}^{c}$ represent the critical fracture energies in the above directions. The fracture energies parallel to the grain $G_{L}^{c}$, perpendicular 
to the grain $G_{T}^{c}$ and $G_{R}^{c}$, and in shear $G_{L R}^{c}, G_{L T}^{c}$ and $G_{R T}^{c}$ were taken from [26] for species of similar density - see summary in Table 4 . While contrary to the other mechanical properties, they were not measured, they were found to correctly reproduce the brittle failure modes as outlined in the results section.

\subsection{Boundary conditions and other parameters}

The boundary conditions are illustrated in Figure 3. To model the rigid connection to the test rig, a stiff plate was tied to the end of the section. A roller-type boundary condition with an imposed rotation was used to apply the moment to the structure and was assigned at the node of the plate corresponding to the centre of the CHS. Due to symmetry conditions and also symmetric of the failure modes, only one-quarter of the beams was modelled and the corresponding symmetric boundary conditions were applied.

8-node linear brick C3D8R elements were used for the timber material. A mesh parametric study showed a nominal element size of $5 \mathrm{~mm}$ to provide accurate results while optimising the computational time. When validating the model, the measured wall thicknesses and diameter for each CHS reported in Table 1 were modelled.

Nonlinear geometric and material conditions and quasi-static implicit dynamic analyses were considered in the models. To improve convergence, viscous regularisation within the cohesive zone element definition was employed. This regularisation was verified to negligibly influence the results, with the energy dissipated by viscoelasticity calculated by the software (ALLCD) at peak load representing less than $0.1 \%$ of the total internal energy of the system (ALLIE).

Note that in the model, only the deterministic size effect $[41,42]$ is considered from the size of the fracture process zones. The statistical size effect [43-45], outlining the difference in volumes between the specimens used to measure the material properties in Table 1 and the tested CHS, is ignored. Further investigation would be needed to understand how this effect influences the capacity of the CHS. 


\section{FINITE ELEMENT RESULTS}

\subsection{Influence of geometric imperfections and compressive failure mode explained}

The model was first run in this section with 18 crack paths in the half-section in compression to produce accurate outcomes and enable any experimental observed crack patterns to develop. The model was used to verify the influence of the cross-sectional imperfections on the results and explain the compressive failure mode. CHS S_G1 was used as a case study as it had both low MOE and wall thickness when compared to the other CHS (Table 1), it was therefore more prone to local buckling and to be sensitive to geometric imperfections. The crack paths were located at $\theta$ in Figure 3 ranging from $5^{\circ}$ to $90^{\circ}$ in $5^{\circ}$ increment. The cross-sectional imperfections were inputted by initially running a linear buckling analysis (LBA) on a "perfect" model. The first local buckling mode was then used as the cross-sectional imperfections by setting the maximum geometric imperfection to $-0.5 \mathrm{~mm}$ (i.e. compression zone at mid-span buckling inward), $0 \mathrm{~mm}$ (no imperfections) and $+0.5 \mathrm{~mm}$ (i.e. compression zone at mid-span buckling outward). This imperfection of $0.5 \mathrm{~mm}$ corresponded to the maximum imperfection typically measured on the CHS tested in [1].

Figure 4 (a) plots the applied moment-curvature relationships for the three models, while Figure 5 shows the evolution of the cross-sectional deformation and the failure mode. The numerical moment was multiplied by 2.0 herein and through this paper to obtain and plot the moment applied to the complete CHS. The curvature was calculated from the same measurements as in $[1,2]$ to allow future comparison with experimental testing. The applied moment-curvature relationships without any crack path are also plotted in Figure 4 (a) for reference.

The results indicate that the sudden failure mode in the compression zone was triggered by local buckling. As the cross-section buckled and deformed (Figure 5 (b) and (c)), the stress perpendicular to the grain in the region between $\theta=30^{\circ}$ and $70^{\circ}$ increased. Fracture eventually occurred in that region, with typically one or two cracks propagating in the CHS longitudinal direction (Figure 5 (d) 
to (f)). When the cracks fully developed, the section opened and the rolling shear near the neutral axis increased until a final crack grew at this location, i.e. at $\theta=90^{\circ}$ (Figure $5(\mathrm{~g})$ and (h)). As shown in Figure 4 (a), if no crack could develop in the compressive zone, a ductile behaviour was encountered. The opening and propagation of the cracks induced the sudden drop of the load after sufficient crosssectional deformation due to buckling occurring. The model was able to well reproduce the failure mode with the deformation in Figure 5 (h) similar to the one observed experimentally in Figure 2 (a).

Figure 4 (a) also indicates that the value of the geometric imperfections influenced the capacity by impacting on the buckling load and buckling deformation which influences the stress distribution and the value of the stress perpendicular to the grain, therefore delaying or not the opening of the cracks. The numerical capacity of the section with $+0.5 \mathrm{~mm}$ imperfections is $8 \%$ higher than the capacity with $-0.5 \mathrm{~mm}$ imperfections as the deformed shape allowed the crack developed. While the imperfections did not impact on the overall structural response, they influenced the number of cracks which propagate and when they propagated. For instance, two cracks fully opened (at $\theta=45^{\circ}$ and $90^{\circ}$ ) for $-0.5 \mathrm{~mm}$ imperfections versus four (at $\theta=5^{\circ}, 35^{\circ}, 65^{\circ}$ and $90^{\circ}$ ) for both $0 \mathrm{~mm}$ (Figure 5 (h)) and $+0.5 \mathrm{~mm}$ imperfections. In all following analyses, as the influence of the imperfections on the capacity, crack propagations and failure mode is not significative, no cross-sectional imperfections were considered.

\subsection{Influence of the number of crack paths in the compressive zone}

As the number of cohesive elements significantly impacts the convergence rate, the influence of the number of crack paths on the structural response was studied hereafter. Considering that in Section 4.1, a minimum of two cracks opened and propagated, the accuracy of the model was verified for this minimum number of observed paths. Five models were run with (1) the first crack path located at $\theta$ (Figure 3) ranging from $30^{\circ}$ to $70^{\circ}$, in $10^{\circ}$ increments, i.e. a path located in the region where the first $\operatorname{crack}(\mathrm{s})$ propagated, and (2) the second path located at $\theta=90^{\circ}$, i.e. at the location of the last crack to open in all analyses. CHS S_G1 was still used as a case study and its moment-curvature relationships are compared in Figure 4 (b) to the more accurate results with 18 crack paths. 
Figure 4 (b) shows that a model with only two crack paths enabled to accurately replicate the moment-curvature response of the reference model with 18 crack paths. The location of the first crack path marginally influenced the non-linear response. The capacities of the five models were within less than $1 \%$ of each other and the minimum capacity of the five models, found for $\theta=50^{\circ}$, was almost identical (1.5\% higher) to the capacity of the reference model. Consequently, to save computational time and as a model with two crack paths enable to accurately replicate the capacity and nonlinear response of the reference model, in all following analyses, only two crack paths were modelled in the compression zone, at $\theta=50^{\circ}$ and $90^{\circ}$.

\subsection{Model validation}

\subsubsection{Capacities, bending stiffness and failure modes}

Table 2 summarises the numerical capacities $M_{b_{-} n u m}$, bending stiffness $E_{L} I_{-n}$ num and failure modes for all CHS reported in Table 1 . The bending stiffness was calculated similarly to the experimental tests by performing a linear regression on the linear part of the numerical moment-curvature curves. Table 2 shows that the models accurately predicted the strength and bending stiffness of the CHS with average experimental to numerical ratios of 1.02 and 0.93 , respectively, with associated coefficients of variation $(\mathrm{CoV})$ of $6.1 \%$ and $14.1 \%$, respectively.

The model correctly predicted the experimentally observed failure modes for eight sections out of ten. Especially, slender $167 \mathrm{~mm} \times 12.5 \mathrm{~mm}$ CHS S_G2 experimentally failed in tension but was predicted to fail in compression. Nevertheless, the bending moments at which all slender CHS would fail in tension were calculating by not modelling the crack paths in the compression zone, therefore preventing the sudden compressive failure mode to develop. These tensile capacities were found to be only up to $1 \%$ higher than the numerical compressive capacities reported in Table 2 . Therefore, for this type of cross-sectional slenderness, as the tensile and compressive strengths are of similar value, either tension or compression failure could occur, rendering the prediction of the correct failure 
mechanism challenging. On the other hand, CHS P2 was predicted to fail in tension but experimentally failed in compression. The numerical compressive capacity of CHS P2 (i.e. by preventing tension failure to develop) was still close to and $5.1 \%$ higher than the numerical tensile capacity in Table 2. The difference between the numerical and experimental failure modes for CHS P2 may be due to the inherent variability in the timber material between the samples used to assess the material strength and the half-section in compression.

\subsubsection{Structural responses}

Figure 6 compares the experimental and numerical moment-curvature curves for all tested CHS. The numerical model generally captured well the overall deformation of the CHS, especially for the compact $167 \mathrm{~mm}$ diameter CHS (Figure 6 (c)) for which significant plastification of the sections in the compression zone occurred before tensile failure.

Figure 7 plots the development of the numerical and experimental strains at mid-span and at the tensile and compressive extreme fibres for the $167 \mathrm{~mm}$ diameter CHS for which the strains were recorded experimentally. The plastification in the compression zone and the buckling of the slender sections was well captured by the model. For S_G2, the numerical strain reversal for the strain gauge in the compression zone indicated that model predicted that the section would buckle outwards whereas tension failure was encountered. For the compact CHS (Figure 7 (b)) and for the strain in the tension zone, the limited non-linearity just before failure was also captured by the model, and reflected the opening of the crack and the length of the fracture process zone [41, 42].

\section{PARAMETRIC STUDY AND DESIGN EQUATIONS}

72 analyses were run using the validated model to understand the relationship between the slenderness ratio and section capacity. The analyses were designed to cover a wide range of realistic cross-sectional slenderness with CHS of diameter $\phi$ ranging from $100 \mathrm{~mm}$ to $500 \mathrm{~mm}$ and wall thickness $t$ from $10 \mathrm{~mm}$ to $50 \mathrm{~mm}$. The influence of various compressive $f_{c, L}$ to tensile $f_{t, L}$ strength ratios parallel to the grain was investigated, with $f_{c, L}$ taken as $50 \mathrm{MPa}$ and $75 \mathrm{MPa}$, and $f_{t, L}$ as $50 \mathrm{MPa}$, 
$85 \mathrm{MPa}$ and $120 \mathrm{MPa}$, representing values encountered for juvenile Gympie messmate [27]. The MOE parallel to the grain $E_{L}$ was set to $18,000 \mathrm{MPa}$. All other parameters were taken as in Table 3 and Table 4. Table 5 lists all analyses performed.

To allow enough length for local buckling to develop, the span of the sections was set to five times the external diameter. The crack path in tension was located at 0.5 times the external diameter from the section end. The numerical capacity $M_{b_{-} \text {num }}$ and failure mode for all analyses are given in Table 5.

Two different slenderness ratios, based on the ones used in steel CHS [46] but adapted to consider the different tensile and compressive strengths encountered in timber, were used to develop design rules. The first slenderness ratio $\lambda_{y_{-} e}$ is based on the "elastic" yield moment $M_{y_{-} e}$, defined as the moment at which the stress at the extreme fibre in tension reaches $f_{t_{-} L}$, assuming an elastic material in compression and without cracks developing in the timber, as shown in Figure 8 (a). $\lambda_{y_{-} e}$ is defined as,

$$
\lambda_{y_{-} e}=\sqrt{\frac{M_{y_{-} e}}{M_{o}} \frac{f_{t_{-} L}}{f_{c_{-} L}}}
$$

where $M_{o}$ is the elastic buckling moment, calculated in the study by performing a linear buckling analysis in Abaqus. In a design situation, $M_{o}$ can be calculated through finite strip analyses for anisotropic material [47] and available software, such as CUFSM [48]. The second slenderness ratio $\lambda_{y_{-} p}$ is based on the "plastic" yield moment $M_{y_{-} p}$, defined as the moment at which the stress at the extreme fibre in tension reaches $f_{t_{L} L}$, assuming an elastic-perfectly plastic material in compression and no cracks developing in the timber, as shown in Figure 8 (b). While the calculation of $M_{y_{-} e}$ is straight forward, an algorithm must be developed to find $M_{y_{-} p}$, such as in [2]. $\lambda_{y_{-} p}$ is defined as,

$$
\lambda_{y_{-} p}=\sqrt{\frac{M_{y_{-} p}}{M_{o}} \frac{f_{t_{-} L}}{f_{c_{-} L}}}
$$


Values of $M_{o}, M_{y_{-} e}$ and $M_{y_{-} p}$ for all analyses are provided in Table 5. Slenderness ratios and their associated "yield" and "plastic" moments are commonly used in structural engineering when developing design equations, such as in [49].

Figure 9 (a) plots the slenderness ratio $\lambda_{y_{-} e}$ versus the normalised capacity $M_{b_{-} n u m} / M_{y_{-} e}$, while Figure 9 (b) plots the $\lambda_{y_{-} p}$ versus $M_{b_{-} n u m} / M_{y_{-} p}$. The two following design equations, in a similar format to design equations used in cold-formed steel [49], are proposed and were found to best estimated the section capacity. Based on $M_{y_{-} e}$, the design capacity $M_{b_{-} d e s i g n}$ is expressed as,

$$
M_{b_{-} \text {design }}=4.82\left(1-0.861 \lambda_{y_{-} e}^{0.144}\right) M_{y_{-} e}
$$

and as follow, based on $M_{y_{-} p}$,

$$
M_{b_{-} \text {design }}=2.72\left(1-0.728 \lambda_{y_{-} p}^{0.295}\right) M_{y_{-} p}
$$

The coefficients in Eqs. (6) and (7) were found by using the Levenberg-Marquardt algorithm and by minimising the sum of the squares of the residuals. Eqs. (6) and (7) are plotted against the parametric results in Figure 9. The experimental results are also plotted in the figure for comparison. The two equations accurately predicted the section capacity with an average numerical to design capacity ratio $M_{b_{-} \text {num }} / M_{b_{-} \text {design }}$ of 1.00 , and associated CoV of $7.93 \%$ (Eq. (6)) and $3.92 \%$ (Eq. (7)). Detailed $M_{b_{-} \text {num }}$ $/ M_{b_{-} \text {design }}$ ratios are given in Table 5. Despite the difficulty in calculating $M_{y_{-}}$, Eq. (7) is more accurate than Eq. (6), as shown in Figure 9 and Table 5.

Eqs. (6) and (7) represent a first attempt to calculate the section capacity of timber CHS. These equations are valid for the studied products, with the butt joint between two half cross-sections in the horizontal plane, and must be verified against experimental and numerical studies performed on CHS manufactured from other species which would have different material properties than the ones considered in Tables 3 and 4. Additional studies are also needed to calculate the capacity factor $\phi$, also referred to as "resistance factors", to safety used the products based on the variability in the predicting equations and timber material properties. 
Note that Figure 9 shows that for compact sections, the section capacity is higher than $M_{y_{-}}$, meaning that some load redistribution occurred at the onset of tensile failure owing to the size of the fracture process zone and the deterministic size effect $[41,42]$. The same phenomenon was observed for the tested compact $167 \mathrm{~mm}$ and $145 \mathrm{~mm}$ diameter CHS which had slenderness ratio $\lambda_{y_{\perp} p}$ between 0.40 and 0.55 , and capacities between 1.12 and 1.19 times higher than associated $M_{y_{-} p}$, as shown in Figure 9.

\section{CONCLUSIONS}

This paper presented a numerical model to capture the structural response of timber CHS loaded in bending. The model used an elastic-perfectly plastic orthotropic material to simulate the ductile compressive failure modes. To account for quasi-brittle tensile and shear failure modes, cohesive elements were used. The model was validated against ten bending tests performed on CHS of different cross-sectional slenderness. Design rules were also proposed. The main findings are summarised below:

- The model was able to accurately predict the overall structural response of the tested CHS. The average experimental-to-numerical strength and bending stiffness ratios were 1.02 and 0.93 , respectively, with associated $\mathrm{CoV}$ of $6.1 \%$ and $14.1 \%$, respectively. Two crack paths in the compression zone were enough to accurately simulate the compressive failure mode.

- The sudden compressive failure mode observed experimentally was shown to be triggered by local buckling. As the cross-section buckled and deformed the stress perpendicular to the grain in the region between $20^{\circ}$ and $70^{\circ}$ (in the CHS cylindrical coordinate system) from the neutral axis increased. Fracture eventually occurred in that region, with typically one or two cracks propagating in the CHS longitudinal direction. When this(ese) $\operatorname{crack}(\mathrm{s})$ fully developed, the section opened and the rolling shear near the neutral axis increased until a final crack grew at this location. 
- Parametric studies were run and used to develop equations to estimate the bending capacity of the analysed sections, therefore leading the way in developing design rules. The proposed equations were found to accurately predict the section capacity of the CHS but need to be verified on CHS manufactured from species different to the one used in the paper.

\section{ACKNOWLEDGMENTS}

The authors are grateful to the Australian Research Council for its financial support through project

DE140100212.

\section{REFERENCES}

[1] B.P. Gilbert, I.D. Underhill, D. Fernando, H. Bailleres, D. Miller "Structural behaviour of hardwood veneer-based circular hollow sections of different compactness", Construction and Building Materials, 170, 557-569 2018.

[2] B.P. Gilbert, I.D. Underhill, H. Bailleres, A. El Hanandeh, R.L. McGavin "Veneer Based Composite hollow utility poles manufactured from hardwood plantation thinned trees", Construction and Building Materials, 66, 458-466, 2014.

[3] T. Hata, K. Umemura, H. Yamauchi, A. Nakayama, S. Kawai, H. Sasaki "Design and pilot production of a spiral-winder for the manufacture of cylindrical laminated veneer lumber", Journal of Wood Science, 47, 115-123, 2001.

[4] P. Berard, P. Yang, H. Yamauchi, K. Umemura, S. Kawai "Modeling of a cylindrical laminated veneer lumber I: mechanical properties of hinoki (Chamaecyparis obtusa) and the reliability of a nonlinear finite elements model of a four-point bending test", Journal of Wood Science, 1-7, 2011.

[5] P. Berard, P. Yang, H. Yamauchi, K. Umemura, S. Kawai "Modeling of a cylindrical laminated veneer lumber II: a nonlinear finite element model to improve the quality of the butt joint", Journal of Wood Science, 1-7, 2011.

[6] J. Wehsener, T. Werner, J. Hartig, P. Haller, "Advancements for the structural application of fiberreinforced moulded wooden tubes", Proceedings of the RILEM Conference "Materials and Joints in Timber Structures - Recent Advancement of Technology" (Eds.: S. Aicher, H.-W. Reinhardt, H. Garrecht), Stuttgart, Germany, 99-108, 2013.

[7] P. Haller, J. Hartig, J. Wehsener, "Application of moulded wooden tubes as structural elements", Proceedings of the 2014 World Conference on Timber Engineering (Ed.: A. Salenikovich), Quebec City, Canada, Paper ABS684, 2014.

[8] L. Wang, W. Liu, D. Hui "Compression strength of hollow sandwich columns with GFRP skins and a paulownia wood core", Composites Part B: Engineering, 60, 495-506, 2014.

[9] R.D. Adams, G.P. Krueger, A.E. Lund, D.D. Nicholas, "Development of utility poles from composite wood material", Proceedings of the 7th IEEE/PES Transmission and Distribution Conference and Exposition (Ed.: IEEE Service center), Atlanta, U.S.A., 37-40, 1979.

[10] C. Piao, Wood laminated composite poles, $\mathrm{PhD}$ Thesis, School of renewable natural ressources, Louisiana State University, Louisiana, U.S.A., 2003.

[11] B.P. Gilbert, I.D. Underhill, D. Fernando, H. Bailleres "Structural solutions to produce long timber Veneer Based Composite hollow sections", Construction and Building Materials, 139, 81-92, 2017. 
[12] S. Hirschmüller, J. Pravida, R. Marte, M. Flach "Long-term material properties of circular hollow laminated veneer lumber sections under water saturation and cement alkaline attack", Wood Material Science \& Engineering, 1-15, 2018.

[13] J.U. Hartig, J. Wehsener, P. Haller "Experimental and theoretical investigations on moulded wooden tubes made of beech (Fagus sylvatica L.)", Construction and Building Materials, 126, 527-536, 2016.

[14] Lignotube, LignoTUBE - the new semi-finished product for lightweight construction, http://lignotube.com/description/, Accessed on.

[15] $\mathrm{K}+\mathrm{W} \quad$ Formholztechnik GmbH, Rings and Tubes, http://www.formholz.de/produkte_und_loesungen/standardprodukte/ringe_und_roehren, Accessed on.

[16] S. Hirschmüller, R. Marte, J. Pravida, M. Flach "Inhibited wood degradation of cement-coated beech Laminated Veneer Lumber (LVL) for temporary in-ground applications", European Journal of Wood and Wood Products, 76, 1483-1494, 2018.

[17] S. Hirschmüller, J. Pravida, R. Marte, M. Flach "Adhesive properties of laminated veneer lumber poles for use in temporary soil nailing: bonding performance of curved structures in a high-alkaline environment", Wood Science and Technology, 52, 1289-1311, 2018.

[18] L. Brancheriau, H. Bailleres "Natural vibration analysis of clear wooden beams: a theoretical review", Wood Science and Technology, 36, 347-365, 2002.

[19] CIRAD, BING ${ }^{\circledR}$ (Beam Identification by Nondestructive Grading) software, https://www.picotech.com/library/application-note/non-destructive-testing-of-wood, Accessed on $25 / 09 / 2015$.

[20] Abaqus, Abaqus ver. 6.14 - User manual, (Dassault Systèmes), Vélizy-Villacoublay, France, 2014.

[21] J.U. Hartig, S. Facchini, P. Haller "Investigations on lateral vehicle impact on moulded wooden tubes made of beech (Fagus sylvatica L.)", Construction and Building Materials, 174, 547-558, 2018.

[22] M. Gharib, A. Hassanieh, H. Valipour, M.A. Bradford "Three-dimensional constitutive modelling of arbitrarily orientated timber based on continuum damage mechanics", Finite Elements in Analysis and Design, 135, 79-90, 2017.

[23] F. Nouri, H.R. Valipour, M.A. Bradford "Finite element modelling of steel-timber composite beam-tocolumn joints with nominally pinned connections", Engineering Structures, 201, 109854, 2019.

[24] A. Hassanieh, H.R. Valipour, M.A. Bradford, C. Sandhaas "Modelling of steel-timber composite connections: Validation of finite element model and parametric study", Engineering Structures, 138, 35-49, 2017.

[25] T. Ghanbari-Ghazijahani, T. Russo, H.R. Valipour "Lightweight timber I-beams reinforced by composite materials", Composite Structures, 233, 111579, 2020.

[26] C. Sandhaas, Mechanical behaviour of timber joints with slotted in steel plates, Thesis, Technische Universiteit Delft,, Technische Universiteit Delft, The Netherlands, 2012.

[27] B.P. Gilbert, H. Bailleres, M.F. Fischer, H. Zhang, R.L. McGavin "Mechanical properties of rotary veneers recovered from early to midrotation subtropical-hardwood plantation logs for veneer-based composite applications.", ASCE Journal of Materials in Civil Engineering, 29, 04017194, 2017.

[28] B.P. Gilbert, J.M. Husson, H. Bailleres, R.L. McGavin, M.F. Fischer "Perpendicular to grain and shear mechanical properties of veneer-based elements glued from single veneer sheets recovered from three species of juvenile subtropical hardwood plantation logs", European Journal of Wood and Wood Products, 76, 1637$1652,2018$.

[29] D.E. Kretschmann, Mechanical Properties of Wood (Chapter 5), in: Wood Handbook, Wood as an engineering material, Forest Products Laboratory, United States Department of Agriculture Forest Service, Madison, Wisconsin, 2010.

[30] B. Franke, P. Quenneville "Numerical Modeling of the Failure Behavior of Dowel Connections in Wood", Journal of Engineering Mechanics, 137, 186-195, 2011.

[31] J. Zhang, M.-J. He, Z. Li "Numerical analysis on tensile performance of bolted glulam joints with initial local cracks", Journal of Wood Science, 64, 364-376, 2018.

[32] B.H. Xu, A. Bouchaïr, P. Racher "Analytical study and finite element modelling of timber connections with glued-in rods in bending", Construction and Building Materials, 34, 337-345, 2012.

[33] EN 408, Timber structures. Structural timber and glued laminated timber. Determination of some physical and mechanical properties, The European Union Per Regulation, Brussel, Belgium, 2010. 
[34] H. Danielsson, P.J. Gustafsson "Fracture analysis of glued laminated timber beams with a hole using a 3D cohesive zone model", Engineering Fracture Mechanics, 124-125, 182-195, 2014.

[35] M. Ardalany, M. Fragiacomo, P. Moss "Modeling of Laminated Veneer Lumber Beams with Holes Using Cohesive Elements", Journal of Structural Engineering, 142, 04015102, 2016.

[36] C. Avez, T. Descamps, E. Serrano, L. Léoskool "Finite element modelling of inclined screwed timber to timber connections with a large gap between the elements", European Journal of Wood and Wood Products, 74, 467-471, 2016.

[37] V.-D. Tran, M. Oudjene, P.-J. Méausoone "FE analysis and geometrical optimization of timber beech finger-joint under bending test", International Journal of Adhesion and Adhesives, 52, 40-47, 2014.

[38] ASTM D143-14, Standard Test Methods for Small Clear Specimens of Timber, ASTM International, Pennsylvania, USA, 2014.

[39] M. Ardalany, B. Deam, M. Fragiacomo, K.I. Crews, "Tension perpendicular to grain strength of wood, Laminated Veneer Lumber (LVL), and Cross-Banded LVL (LVL-C)", Proceedings of the Proceedings of the 21st Australasian Conference on the Mechanics of Structures and Materials (ACMSM21), 891 - 896, 2011.

[40] R.L. McGavin, H.H. Nguyen, B.P. Gilbert, T. Dakin, A. Faircloth "A comparative study on the mechanical properties of laminated veneer lumber (LVL) produced from blending various wood veneers", BioRessources, 14, 9064-9081, 2019.

[41] Z.P. Bažant, W.P. Murphy, "Probabilistic modeling of quasibrittle fracture and size effect", Proceedings of the Proc.eedings of the 8th International Conference on Structural Safety and Reliability (ICOSSAR) (Ed.: Swets \& Zeitinger), California, USA, 1-23, 2001.

[42] Z.P. Bažant, S.D. Pang, M. Vořechovsky, D. Novák, R. Pukl, "Statistical size effect in quasibrittle materials: Computation and extreme value theory." Fracture Mechanics of Concrete Structures ", Proceedings of the 5th International Conference on Fracture Mechanics of Concrete and Concrete Structures (Eds.: V.C. Li, K.Y. Leung, K.J. Willam, S.L. Billington), Vail, U.S.A., 189--196., 2004.

[43] W. Weibull, A statistical theory of strength of materials, Generalstabens litografiska anstalts förlag, Stockholm, 1939.

[44] J.D. Barrett, F. Lam, W. Lau "Size Effects in Visually Graded Softwood Structural Lumber", ASCE Journal of Materials in Civil Engineering, 7, 19-30, 1995.

[45] B. Madsen, A.H. Buchanan "Size effect in timber explained by a modified weakest link theory", Canadian Journal of Civil Engineering, 13, 218-232, 1986.

[46] O. Zhao, L. Gardner, B. Young "Structural performance of stainless steel circular hollow sections under combined axial load and bending - Part 2: Parametric studies and design", Thin-Walled Structures, 101, 240248, 2016.

[47] G. Akhras, M.S. Cheung, W. Li "Finite strip analysis of anisotropic laminated composite plates using higher-order shear deformation theory", Computers \& Structures, 52, 471-477, 1994.

[48] B.W. Schafer, S. Adany, "Buckling analysis of cold-formed steel members using CUFSM: conventional and constrained finite strip methods", Proceedings of the 18th International Specialty Conference on ColdFormed Steel Structures (Eds.: R.A. LaBoule, W.W. Yu), Orlando, Florida, U.S.A., 39-54, 2006.

[49] B.W. Schafer "Review: The Direct Strength Method of cold-formed steel member design", Journal of Constructional Steel Research, 64, 766-778, 2008. 


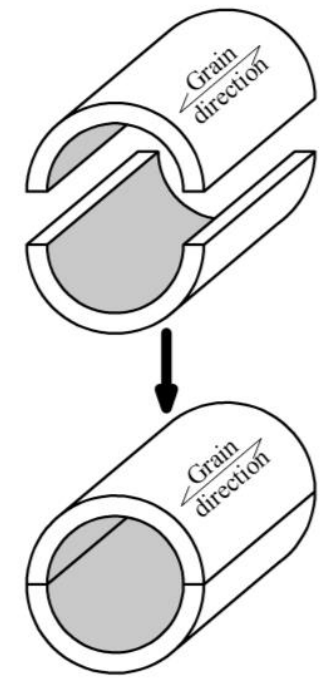

(a)

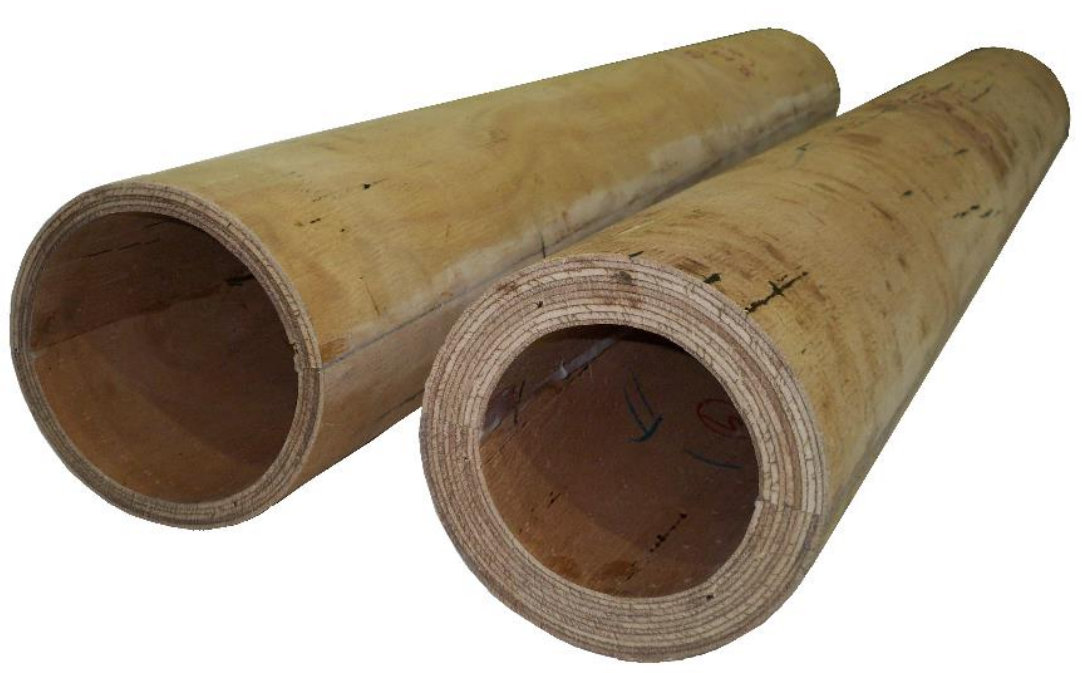

(b)

Figure 1: (a) Manufacturing concept and (b) examples of manufactured sections in [1]

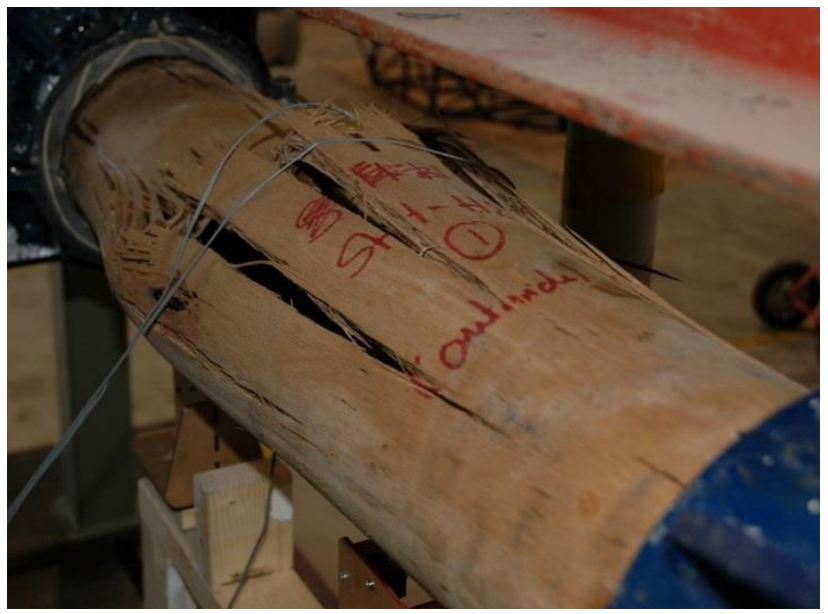

(a)

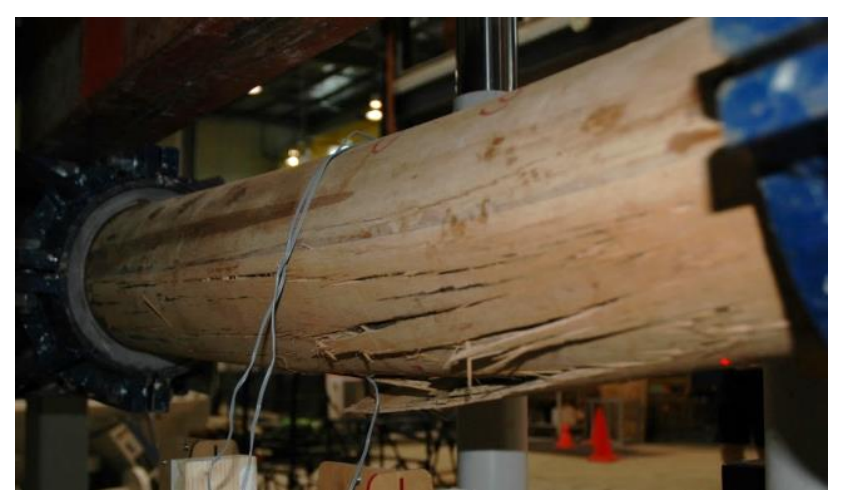

(b)

Figure 2: (a) Sudden compressive and (b) tensile failure modes in [1] 


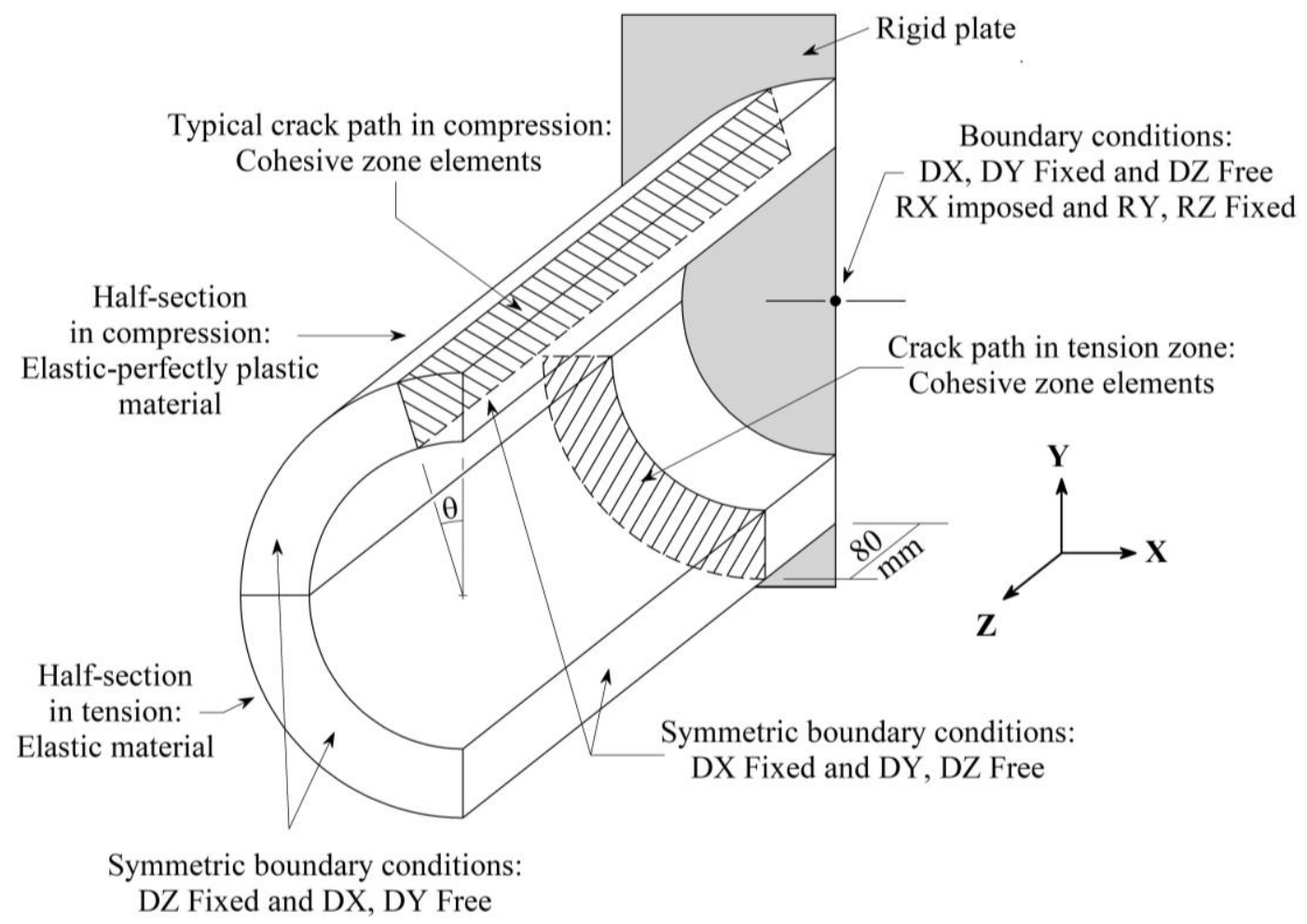

Figure 3: Schematic FE model of a CHS beam 


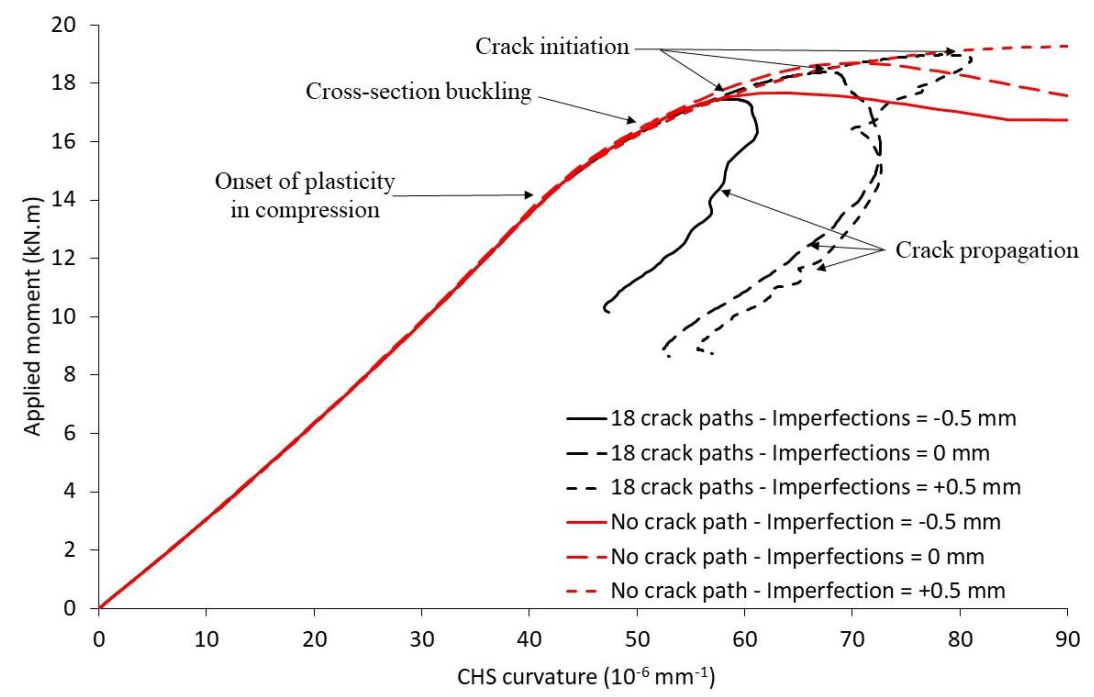

(a)

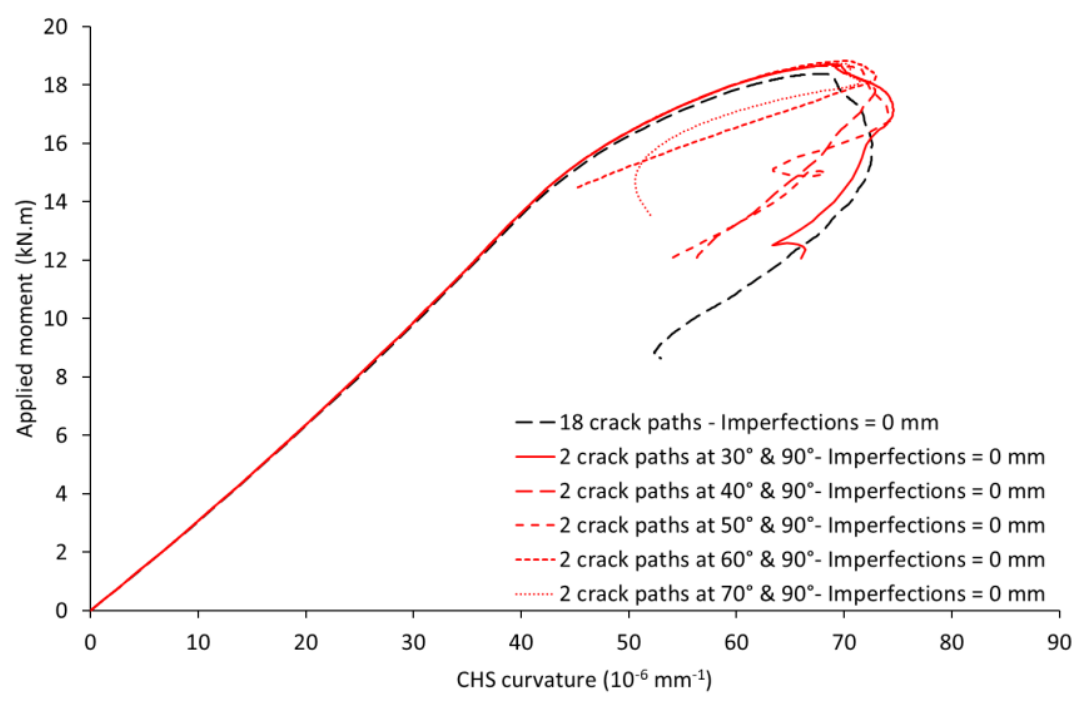

(b)

Figure 4: Moment-curvature results, influence of (a) geometric imperfections and (b) number of crack paths - CHS S_G1 


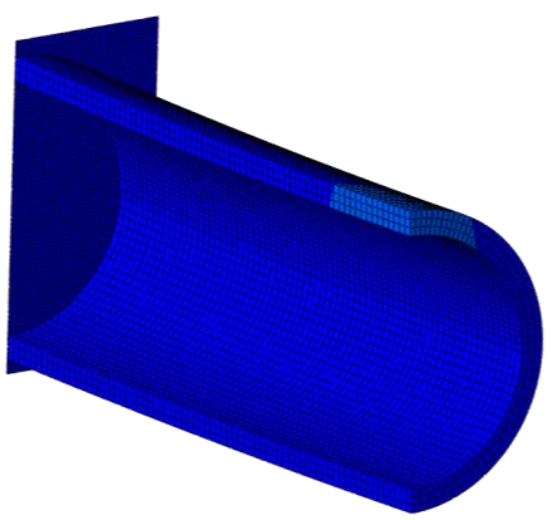

(a)

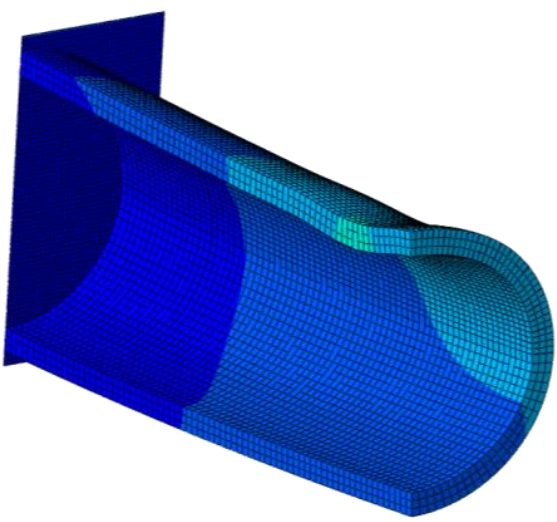

(c)

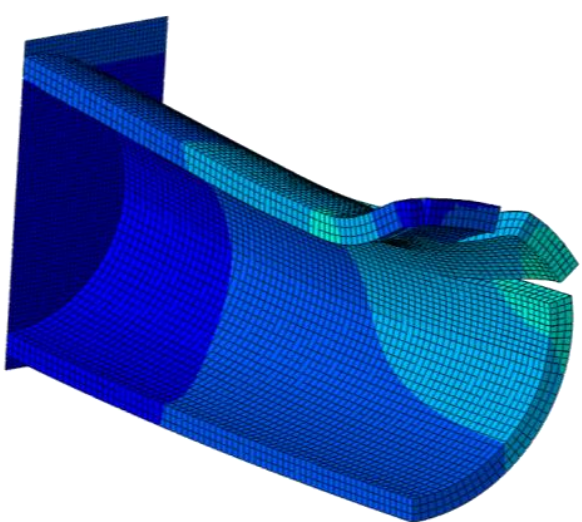

(e)

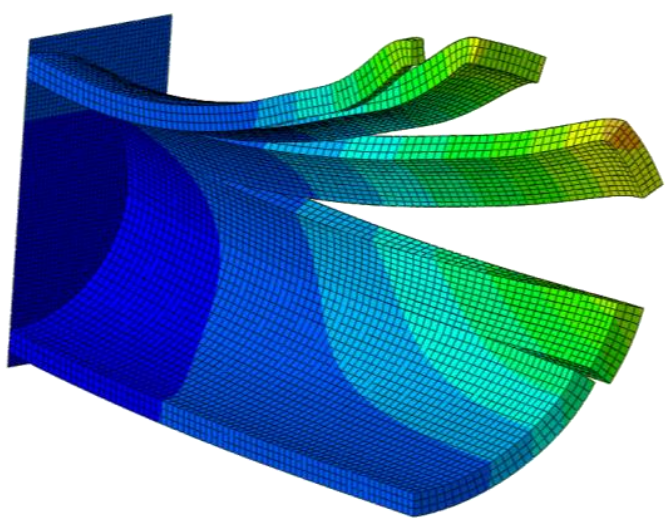

(g)

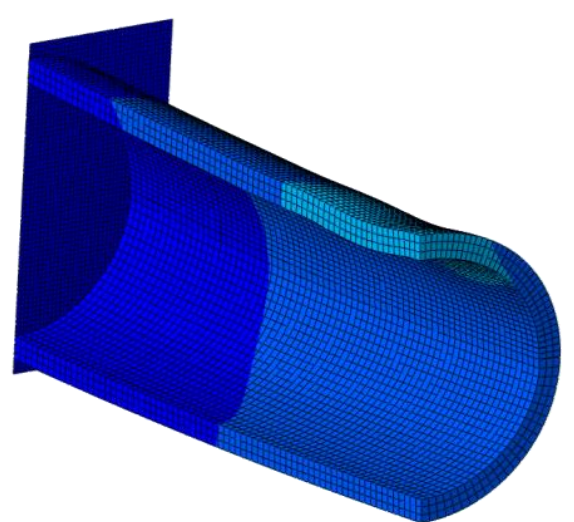

(b)

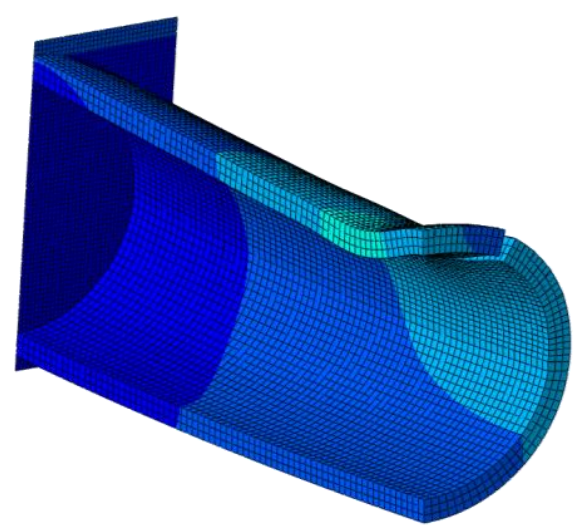

(d)

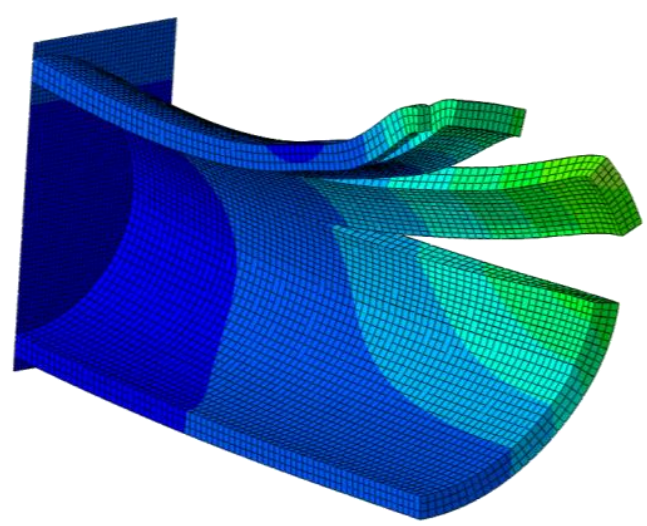

(f)

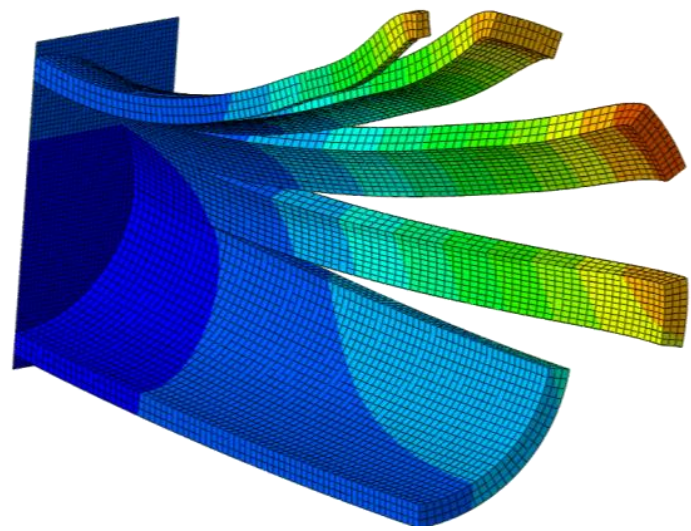

(h)

Figure 5: Cross-sectional deformation, with a deformation scale factor of 3.0, for 18 crack paths in compression zone for imperfections $=0 \mathrm{~mm}$, (a) onset of plastification, (b) during buckling, (c) at crack initiation (maximum load), (d) beginning of crack propagation and (e-h) through crack propagation 


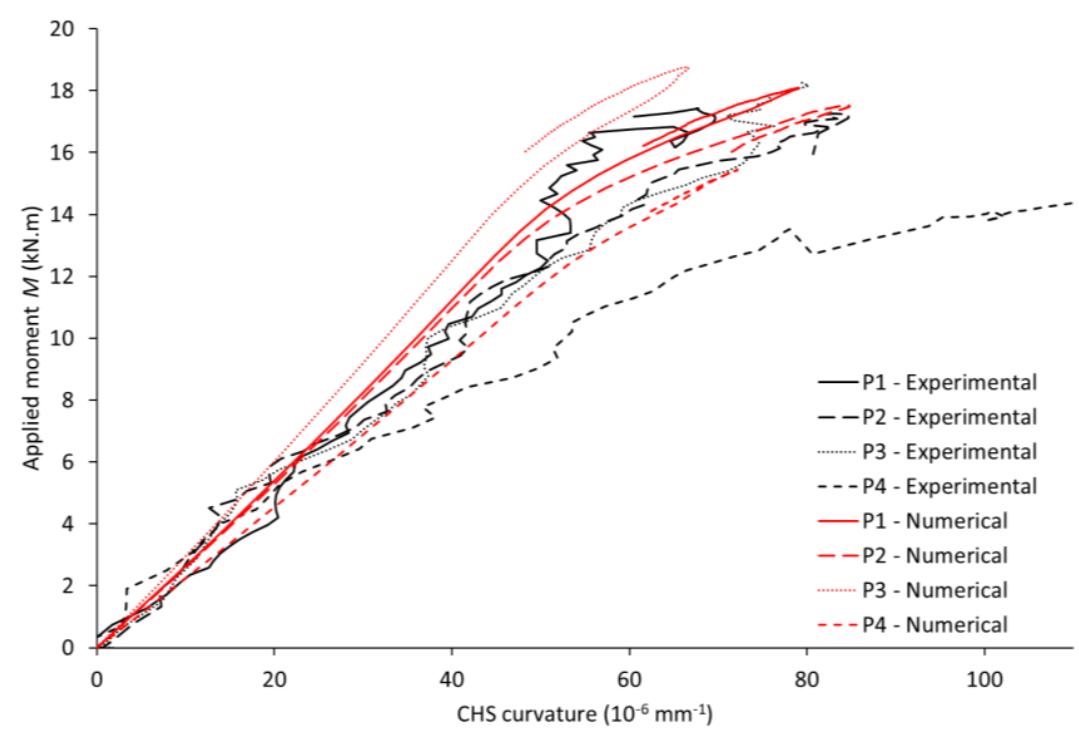

(a)

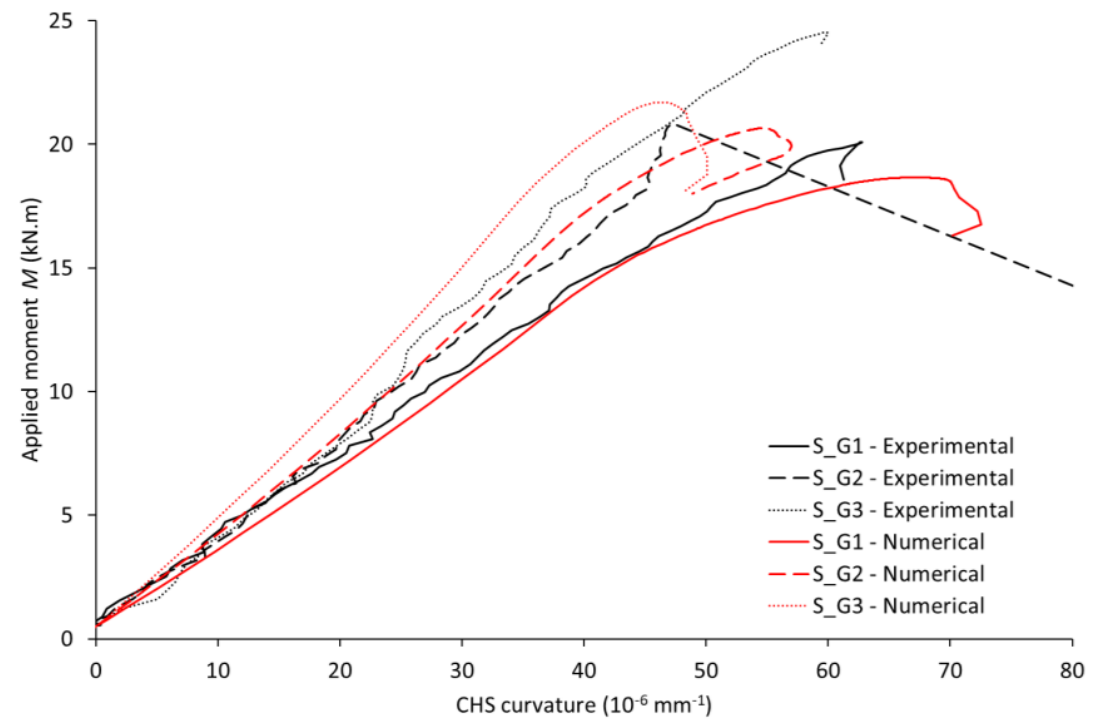

(b)

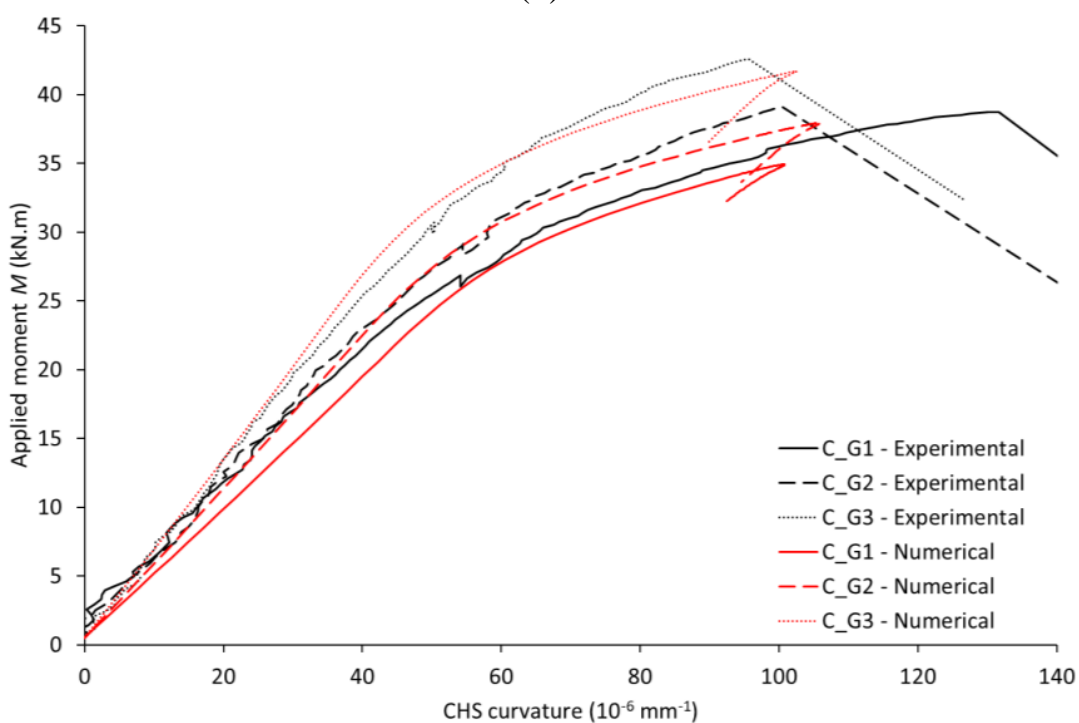

(c)

Figure 6: Numerical versus experimental moment-curvature curves for (a) $145 \mathrm{~mm} \times 15 \mathrm{~mm}$ CHS, (b) 167 $\mathrm{mm} \times 12.5 \mathrm{~mm} \mathrm{CHS}$ and (c) ) $167 \mathrm{~mm} \times 25 \mathrm{~mm} \mathrm{CHS}$ 


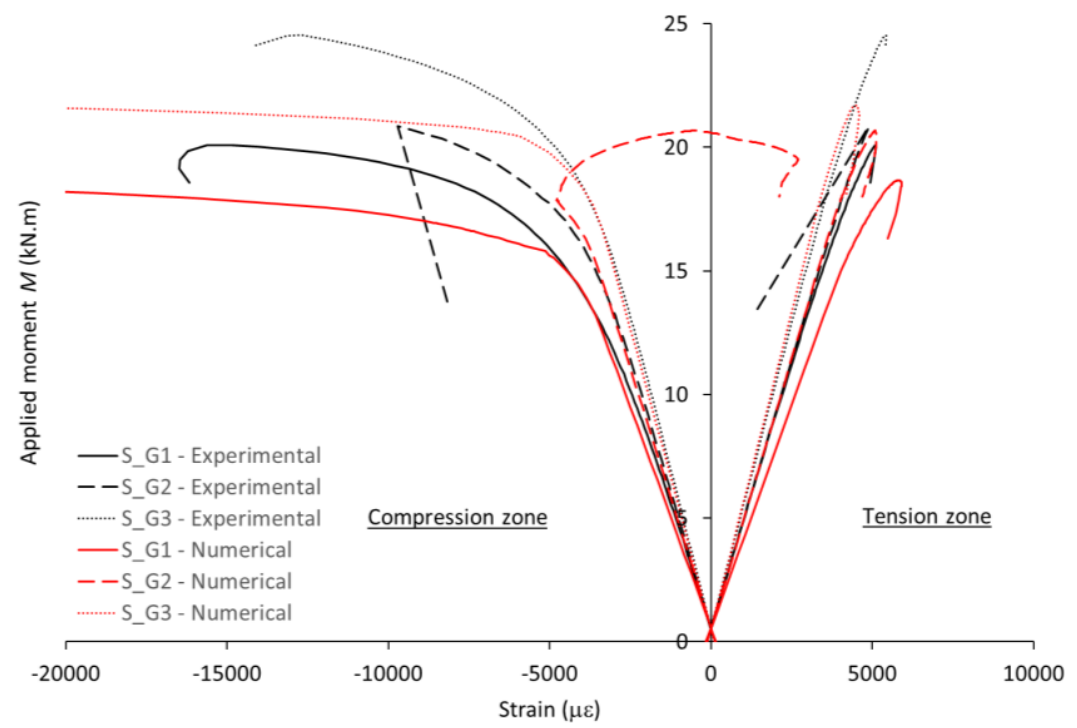

(a)

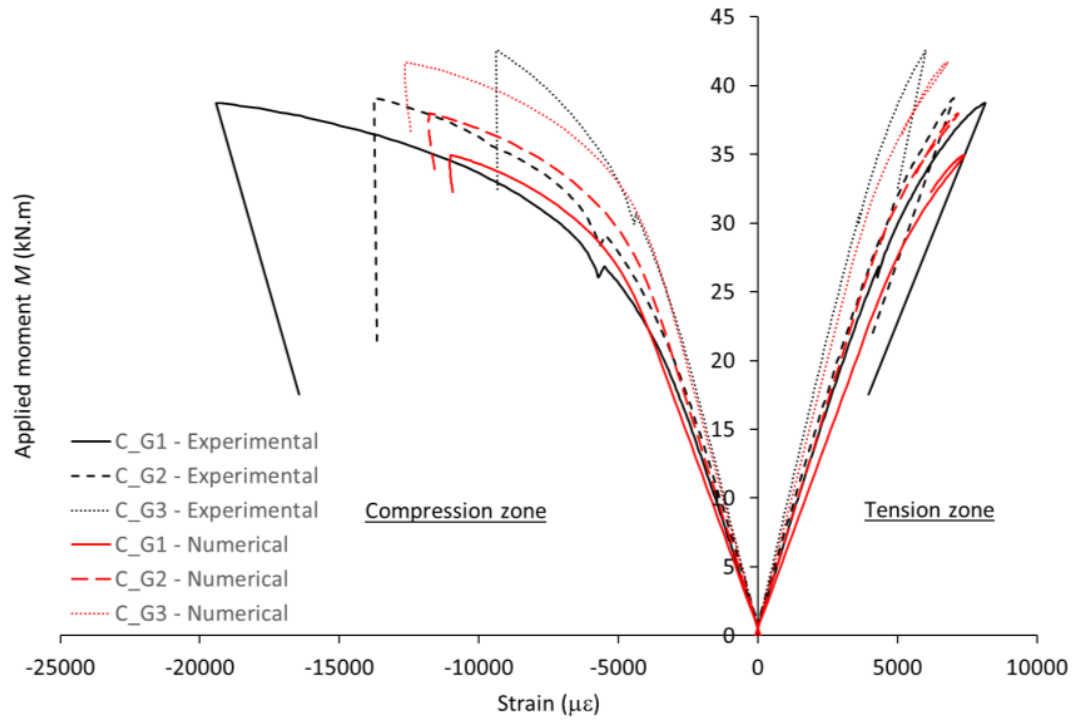

(b)

Figure 7: Numerical versus experimental strain development for (a) $167 \mathrm{~mm} \times 12.5 \mathrm{~mm}$ CHS and (b) 167 $\mathrm{mm} \times 25 \mathrm{~mm}$ CHS 


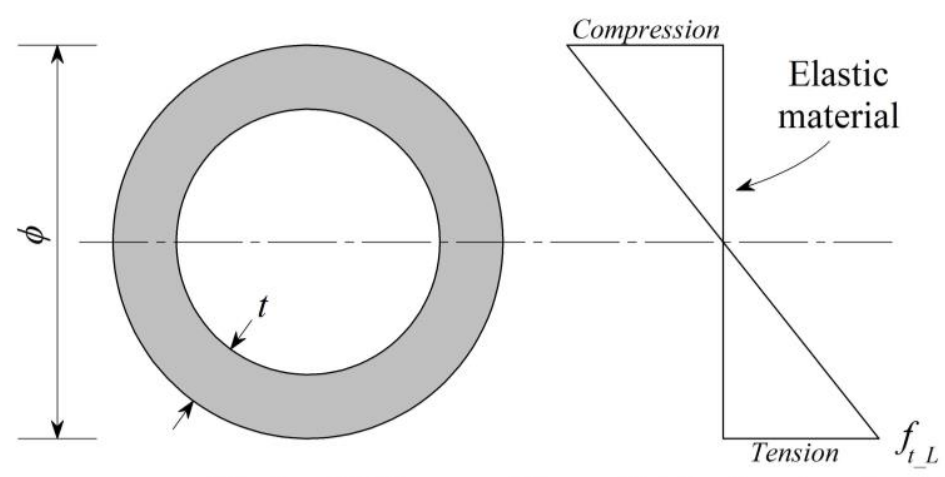

Timber CHS Stress distribution to calculate $M_{y_{e}}$

(a)

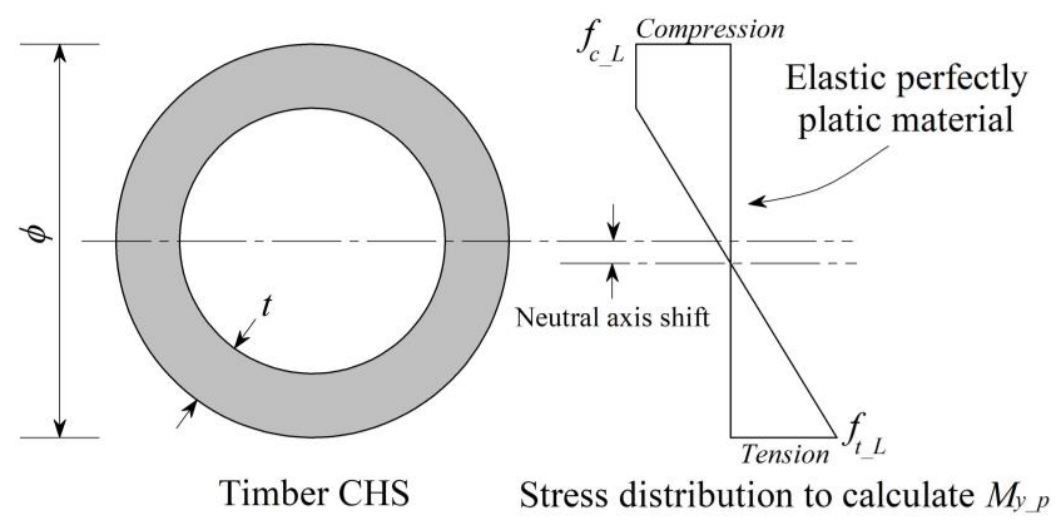

(b)

Figure 8: Stress distribution to calculate (a) $M_{y_{-} e}$ and (b) $M_{y_{-} p}$ 


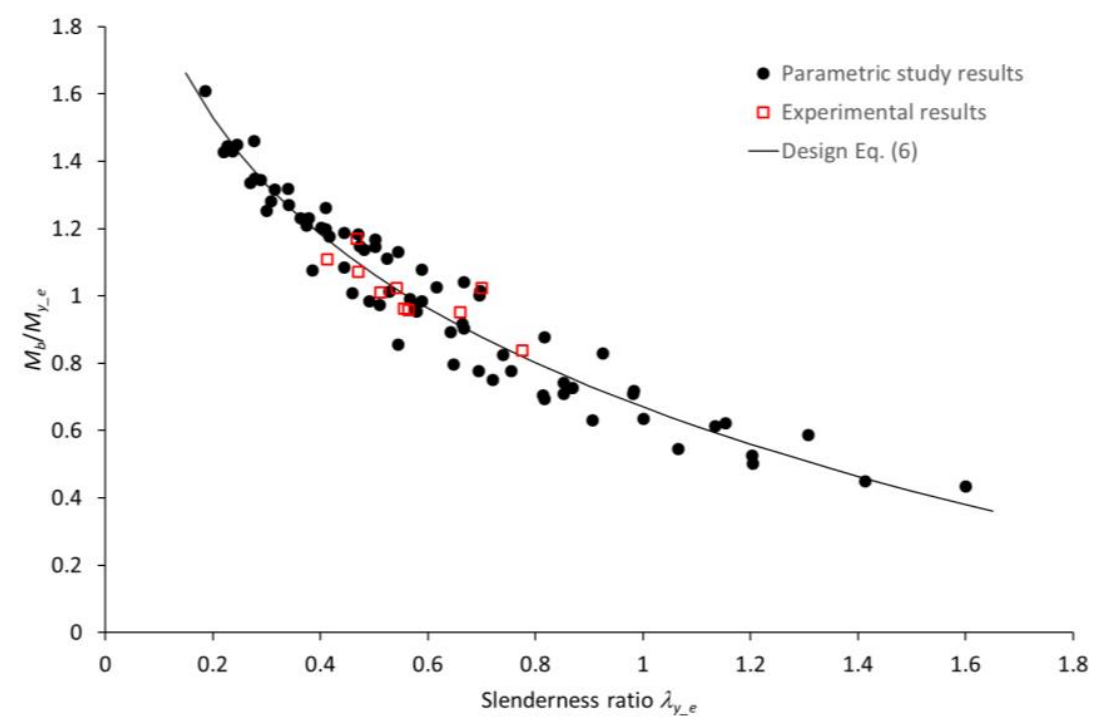

(a)

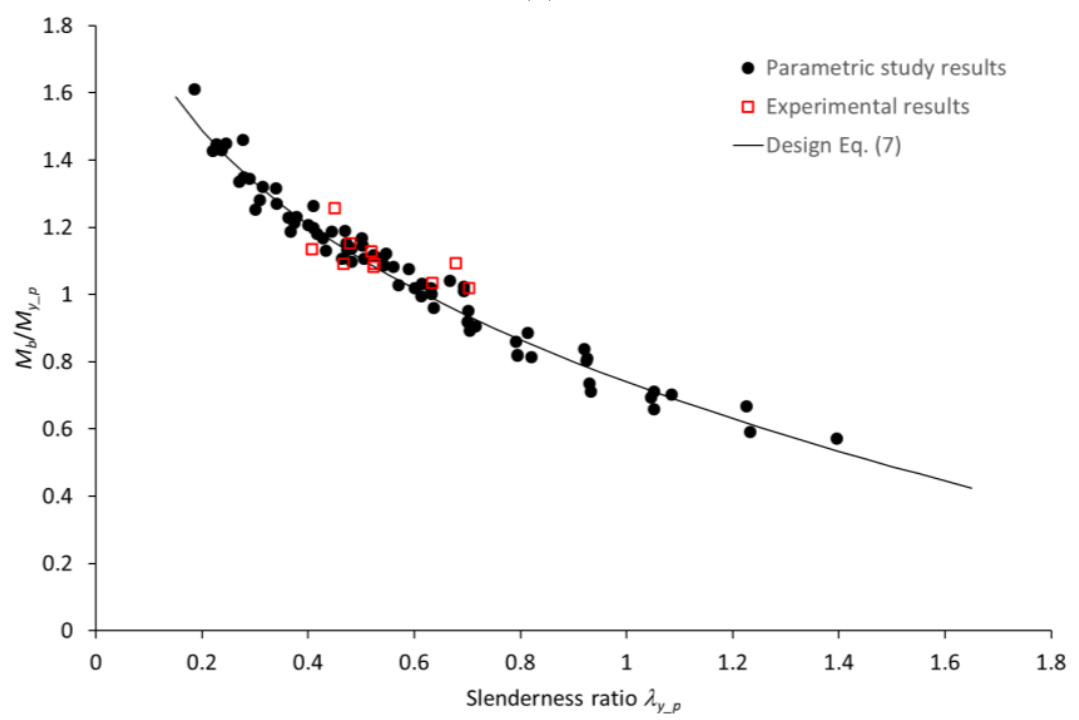

(b)

Figure 9: Parametric study results, slenderness ratio versus normalised capacity (a) $\lambda_{y_{-} e}$ versus $M_{b} / M_{y_{-} e}$ and (b) $\lambda_{y_{-} p}$ versus $M_{b} / M_{y_{-} p}$ 
Table 1: Dimensions and properties of tested CHS beams in $[1,2]$

\begin{tabular}{|c|c|c|c|c|c|c|c|c|c|}
\hline \multirow[b]{2}{*}{ Section } & \multirow[b]{2}{*}{$\begin{array}{l}\text { Nominal dimen- } \\
\text { sions (mm) }\end{array}$} & \multicolumn{2}{|c|}{$\begin{array}{l}\text { Measured } \\
\text { dimensions }\end{array}$} & \multicolumn{3}{|c|}{$\begin{array}{c}\text { Half section in compression - } \\
\text { Measured properties }\end{array}$} & \multicolumn{3}{|c|}{$\begin{array}{l}\text { Half section in tension - } \\
\text { Measured properties }\end{array}$} \\
\hline & & $\begin{array}{c}\operatorname{Span} L \\
(\mathrm{~mm})\end{array}$ & $\begin{array}{l}\text { Diam. } \\
(\mathrm{mm})\end{array}$ & $\begin{array}{c}t \\
(\mathrm{~mm})\end{array}$ & $\begin{array}{c}E_{L} \\
(\mathrm{MPa})\end{array}$ & $\begin{array}{c}f_{c, L} \\
(\mathrm{MPa})\end{array}$ & $\begin{array}{c}t \\
(\mathrm{~mm})\end{array}$ & $\begin{array}{c}E_{L} \\
(\mathrm{MPa})\end{array}$ & $\begin{array}{c}f_{t, L} \\
(\mathrm{MPa})\end{array}$ \\
\hline P1 & $145 \times 15$ & 6660 & 147 & 15.8 & $17,900^{(1)}$ & 61.3 & 15.8 & $1919,200^{(1)}$ & 94.7 \\
\hline $\mathrm{P} 2$ & $145 \times 15$ & 660 & 146 & 15.1 & $17,900^{(1)}$ & 60.8 & 15.6 & $19,100^{(1)}$ & 90.3 \\
\hline P3 & $145 \times 15$ & 660 & 148 & 16.0 & $20,900^{(1)}$ & 66.2 & 15.7 & $18,800^{(1)}$ & 84.9 \\
\hline $\mathrm{P} 4$ & $145 \times 15$ & 660 & 145 & 16.8 & $15,800^{(1)}$ & 55.9 & 16.4 & $15,700^{(1)}$ & 68.5 \\
\hline S_G1 & $167 \times 12.5$ & 720 & 164 & 13.4 & $16,723^{(2)}$ & 58.6 & 12.6 & $16,693^{(2)}$ & 109.5 \\
\hline S_G2 & $167 \times 12.5$ & 720 & 165 & 12.9 & $19,855^{(2)}$ & 69.2 & 12.9 & $19,637^{(2)}$ & 101.5 \\
\hline S_G3 & $167 \times 12.5$ & 720 & 165 & 12.3 & $23,707^{(2)}$ & 77.9 & 12.7 & $23,347^{(2)}$ & 114.0 \\
\hline C_G1 & $167 \times 25$ & 720 & 164 & 25.3 & $16,953^{(2)}$ & 64.4 & 24.9 & $16,505^{(2)}$ & 99.3 \\
\hline C_G2 & $167 \times 25$ & 720 & 162 & 26.4 & $19,637^{(2)}$ & 66.7 & 25.6 & $20,116^{(2)}$ & 117.2 \\
\hline C_G3 & $167 \times 25$ & 720 & 164 & 25.5 & $22,417^{(2)}$ & 71.3 & 24.9 & $23,755^{(2)}$ & 133.0 \\
\hline
\end{tabular}

(1) Value measured from an extensometer during material testing

(2) Value taken as the average measured dynamic MOE of all veneers

Table 2: Experimental capacity and failure modes in $[1,2]$ versus numerical solutions

\begin{tabular}{|c|c|c|c|c|c|c|c|c|c|}
\hline \multirow[b]{2}{*}{ Name } & \multirow[b]{2}{*}{$\begin{array}{l}\text { Nominal dimen- } \\
\text { sions }(\mathrm{mm})\end{array}$} & \multicolumn{3}{|c|}{ Experimental results } & \multicolumn{3}{|c|}{ Numerical results } & \multicolumn{2}{|c|}{$\begin{array}{l}\text { Experimental. to } \\
\text { numerical ratios }\end{array}$} \\
\hline & & $\begin{array}{l}M_{b_{-} \exp } \\
\text { (kN.m) }\end{array}$ & $\begin{array}{c}E_{L} I_{\text {exp }} \\
\left(\mathrm{kN} \cdot \mathrm{m}^{2}\right)\end{array}$ & $\begin{array}{l}\text { Failure } \\
\text { mode }\end{array}$ & $\begin{array}{l}M_{b_{\perp} \text { num }} \\
\text { (kN.m) }\end{array}$ & $\begin{array}{l}E_{L} I_{- \text {num }} \\
\left(\mathrm{kN} . \mathrm{m}^{2}\right)\end{array}$ & $\begin{array}{c}\text { Failure } \\
\text { mode }\end{array}$ & $\begin{array}{l}M_{b_{-} \text {exp }} / \\
M_{b_{\text {nnum }}}\end{array}$ & $\begin{array}{l}E_{L} I_{-\exp } / \\
E_{L} I_{\text {nит }}\end{array}$ \\
\hline P1 & $145 \times 15$ & 17.6 & 267 & Tension $^{(1)}$ & 18.1 & 279 & Tension & 0.97 & 0.96 \\
\hline $\mathrm{P} 2$ & $145 \times 15$ & 17.1 & 230 & Compression & 17.5 & 273 & Tension & 0.98 & 0.84 \\
\hline P3 & $145 \times 15$ & 18.0 & 228 & Tension $^{(1)}$ & 18.8 & 309 & Tension & 0.96 & 0.74 \\
\hline $\mathrm{P} 4$ & $145 \times 15$ & 14.8 & 160 & Tension $^{(1)}$ & 15.4 & 234 & Tension & 0.96 & 0.68 \\
\hline S_G1 & $167 \times 12.5$ & 20.1 & 342 & Compression & 18.7 & 347 & Compression & 1.08 & 0.98 \\
\hline S_G2 & $167 \times 12.5$ & 21.0 & 419 & Tension & 20.7 & 415 & Compression & 1.01 & 1.01 \\
\hline S_G3 & $167 \times 12.5$ & 24.6 & 476 & Compression & 21.7 & 486 & Compression & 1.13 & 0.98 \\
\hline C_G1 & $167 \times 25$ & 38.7 & 507 & Tension & 34.9 & 475 & Tension & 1.11 & 1.07 \\
\hline C_G2 & $167 \times 25$ & 39.1 & 578 & Tension $^{(1)}$ & 38.0 & 548 & Tension & 1.03 & 1.06 \\
\hline C_G3 & $167 \times 25$ & 42.6 & 635 & Tension $^{(1)}$ & 41.7 & 656 & Tension & 1.02 & 0.97 \\
\hline & & & & & & & Average & 1.02 & 0.93 \\
\hline & & & & & & & $\operatorname{CoV}(\%)$ & 6.1 & 14.1 \\
\hline
\end{tabular}

(1) Failure occurred at the test rig connections for this test and the maximum bending moment reached is considered herein as the tensile capacity (see Section 2). Therefore, for comparison to the numerical model, this failure mode can be regarded as tensile failure.

Table 3: Elastic properties taken in model validation

\begin{tabular}{|c|c|c|c|c|c||}
\hline \hline$E_{L}(\mathrm{MPa})$ & $E_{T}, E_{R}(\mathrm{MPa})$ & $G_{L T}, G_{L R}(\mathrm{MPa})$ & $G_{R T}(\mathrm{MPa})$ & $\gamma_{L R}, \gamma_{L T}$ & $\gamma_{R T}$ \\
\hline \hline From Table 1 & 800 & 750 & 200 & 0.4 & 0.5 \\
\hline \hline
\end{tabular}

Table 4: Strengths and fracture energies taken in model validation

\begin{tabular}{|c|c||c|c|c|c||c|c|c|c||}
\hline \multicolumn{2}{|c|}{ Compressive strengths } & \multicolumn{2}{|c|}{ Tensile strengths } & \multicolumn{2}{|c|}{ Shear strengths } & \multicolumn{4}{c||}{ Critical fracture energies } \\
\hline \hline $\begin{array}{c}f_{c, L} \\
(\mathrm{MPa})\end{array}$ & $\begin{array}{c}f_{c, T}, f_{c, R} \\
(\mathrm{MPa})\end{array}$ & $\begin{array}{c}f_{t, L} \\
(\mathrm{MPa})\end{array}$ & $\begin{array}{c}f_{t, T}, f_{t, R} \\
(\mathrm{MPa})\end{array}$ & $\begin{array}{c}f_{s, L T}, f_{s, L R} \\
(\mathrm{MPa})\end{array}$ & $\begin{array}{c}f_{s, R T} \\
(\mathrm{MPa})\end{array}$ & $\begin{array}{c}G_{L}^{c} \\
(\mathrm{~N} / \mathrm{mm})\end{array}$ & $\begin{array}{c}G_{T}^{c}, G_{R}^{c} \\
(\mathrm{~N} / \mathrm{mm})\end{array}$ & $\begin{array}{c}G_{L T}^{c}, G_{L R}^{c} \\
(\mathrm{~N} / \mathrm{mm})\end{array}$ & $\begin{array}{c}G_{R T}^{c} \\
(\mathrm{~N} / \mathrm{mm})\end{array}$ \\
\hline \hline $\begin{array}{c}\text { From } \\
\text { Table 1 }\end{array}$ & $13.3^{(1)}$ & $\begin{array}{c}\text { From } \\
\text { Table 1 }\end{array}$ & $2.7^{(2)}$ & 10.0 & 2.5 & 180 & 0.7 & 1.2 & 0.6 \\
\hline
\end{tabular}

(1) Average results on five tests performed as part of this study with a Coefficient of Variation of $2.6 \%$

(2) Average results on five tests performed as part of this study with a Coefficient of Variation of $17.2 \%$ 
Table 5: Parametric study and design rules results

\begin{tabular}{|c|c|c|c|c|c|c|c|c|c|c|c|c|c|c|c|c|c|c|c|c|c|}
\hline $\begin{array}{c}\phi \\
(\mathrm{mm})\end{array}$ & $\begin{array}{c}t \\
(\mathrm{~mm})\end{array}$ & $\begin{array}{c}f_{c, L} \\
(\mathrm{MPa})\end{array}$ & $\begin{array}{c}f_{t, L} \\
(\mathrm{MPa})\end{array}$ & $\begin{array}{c}M_{o} \\
(\mathrm{kN} . \mathrm{m})\end{array}$ & $\mid \begin{array}{c}M_{y_{-} e} \\
(\mathrm{kN} . \mathrm{m})\end{array}$ & $\begin{array}{c}M_{y_{-} p} \\
(\mathrm{kN} . \mathrm{m})\end{array}$ & $\mid \begin{array}{l}M_{b_{-} \text {num }} \\
(\mathrm{kN} . \mathrm{m})\end{array}$ & $\begin{array}{l}\text { Fail- } \\
\text { ure }^{(1)}\end{array}$ & \begin{tabular}{|l|}
$M_{b \_n u m}$ \\
$M_{b \_ \text {design }}$ \\
Eq. (6)
\end{tabular} & \begin{tabular}{|c|}
$M_{b \_n u m}$ \\
$M_{b_{\_} \text {design }}$ \\
Eq. (7)
\end{tabular} & $\begin{array}{c}\phi \\
(\mathrm{mm})\end{array}$ & $\begin{array}{c}t \\
(\mathrm{~mm})\end{array}$ & $\begin{array}{c}f_{c, L} \\
(\mathrm{MPa})\end{array}$ & $\begin{array}{c}f_{t, L} \\
(\mathrm{MPa})\end{array}$ & $\begin{array}{c}M_{o} \\
\text { (kN.m) }\end{array}$ & $\begin{array}{c}M_{y_{-} e} \\
(\mathrm{kN} . \mathrm{m})\end{array}$ & $\begin{array}{c}M_{y_{-} p} \\
(\mathrm{kN} . \mathrm{m})\end{array}$ & $\begin{array}{l}M_{b_{\_} \text {num }} \\
(\mathrm{kN} . \mathrm{m})\end{array}$ & $\begin{array}{l}\text { Fail- } \\
\text { ure }^{(1)}\end{array}$ & \begin{tabular}{|c}
$M_{b \_n u m} /$ \\
$M_{b \_d e s i g n}$ \\
Eq. (6)
\end{tabular} & $\begin{array}{c}M_{b \_n u m} \\
M_{b \_d e s i g n} \\
\text { Eq. (7) }\end{array}$ \\
\hline \multirow{12}{*}{100} & \multirow{6}{*}{10} & \multirow{3}{*}{50} & 50 & \multirow{6}{*}{25.2} & 2.9 & 2.9 & 3.8 & $\mathrm{~T}$ & 1.04 & 1.03 & \multirow{12}{*}{300} & \multirow{6}{*}{25} & \multirow{3}{*}{50} & 50 & \multirow{6}{*}{482.0} & 68.6 & 68.6 & 84.5 & $\mathrm{~T}$ & 1.01 & 1.00 \\
\hline & & & 85 & & 4.9 & 4.3 & 4.8 & $\mathrm{C}$ & 0.98 & 1.04 & & & & 85 & & 116.7 & 102.1 & 104.1 & $\mathrm{C}$ & 0.96 & 1.00 \\
\hline & & & 120 & & 7.0 & 5.2 & 4.9 & $\mathrm{C}$ & 0.89 & 1.02 & & & & 120 & & 164.7 & 126.7 & 104.1 & $\mathrm{C}$ & 0.87 & 0.95 \\
\hline & & \multirow{3}{*}{75} & 50 & & 2.9 & 2.9 & 4.2 & $\mathrm{~T}$ & 1.07 & 1.07 & & & \multirow{3}{*}{75} & 50 & & 68.6 & 68.6 & 88.0 & $\mathrm{~T}$ & 0.97 & 0.97 \\
\hline & & & 85 & & 4.9 & 4.9 & 5.8 & $\mathrm{~T}$ & 1.08 & 1.05 & & & & 85 & & 116.7 & 116.0 & 129.6 & $\mathrm{~T}$ & 1.07 & 1.03 \\
\hline & & & 120 & & 7.0 & 6.3 & 6.4 & $\mathrm{C}$ & 1.01 & 1.03 & & & & 120 & & 164.7 & 147.7 & 135.9 & $\mathrm{~T}$ & 0.97 & 0.98 \\
\hline & \multirow{6}{*}{20} & \multirow{3}{*}{50} & 50 & \multirow{6}{*}{83.3} & 4.3 & 4.3 & 6.2 & $\mathrm{~T}$ & 0.98 & 1.00 & & \multirow{6}{*}{40} & \multirow{3}{*}{50} & 50 & \multirow{6}{*}{1129} & 94.2 & 94.2 & 126.7 & $\mathrm{~T}$ & 1.00 & 1.00 \\
\hline & & & 85 & & 7.3 & 6.6 & 7.8 & $\mathrm{~T}$ & 0.90 & 0.95 & & & & 85 & & 160.2 & 142.4 & 157.8 & $\mathrm{~T}$ & 0.92 & 0.97 \\
\hline & & & 120 & & 10.3 & 7.7 & 8.8 & $\mathrm{~T}$ & 0.84 & 1.00 & & & & 120 & & 226.1 & 176.3 & 175.7 & $\mathrm{~T}$ & 0.88 & 0.99 \\
\hline & & \multirow{3}{*}{75} & 50 & & 4.3 & 4.3 & 6.9 & $\mathrm{~T}$ & 1.03 & 1.06 & & & \multirow{3}{*}{75} & 50 & & 94.2 & 94.2 & 134.8 & $\mathrm{~T}$ & 0.99 & 1.00 \\
\hline & & & 85 & & 7.3 & 7.2 & 9.6 & $\mathrm{~T}$ & 1.01 & 1.01 & & & & 85 & & 160.2 & 159.5 & 192.6 & $\mathrm{~T}$ & 1.02 & 1.00 \\
\hline & & & 120 & & 10.3 & 9.5 & 11.1 & $\mathrm{~T}$ & 0.96 & 0.99 & & & & 120 & & 226.1 & 206.0 & 224.2 & $\mathrm{~T}$ & 1.00 & 1.02 \\
\hline \multirow{18}{*}{200} & & & 50 & & 13.5 & 13.5 & 15.8 & $\mathrm{C}$ & 1.10 & 1.06 & & & & 50 & & 84.2 & 84.2 & 90.7 & $\mathrm{C}$ & 1.11 & 1.05 \\
\hline & & 50 & 85 & & 23.0 & 19.8 & 17.1 & $\mathrm{C}$ & 0.97 & 0.99 & & & 50 & 85 & & 143.1 & 123.5 & 91.0 & $\mathrm{C}$ & 0.95 & 0.94 \\
\hline & 10 & & 120 & & 32.4 & 24.5 & 17.1 & $\mathrm{C}$ & 0.94 & 0.97 & & & & 120 & 2121 & 202.0 & 153.9 & 91.0 & $\mathrm{C}$ & 0.98 & 0.96 \\
\hline & 10 & & 50 & 53.9 & 13.5 & 13.5 & 17.1 & $\mathrm{~T}$ & 1.08 & 1.05 & & 15 & & 50 & 243.1 & 84.2 & 84.2 & 95.8 & $\mathrm{~T}$ & 1.05 & 1.01 \\
\hline & & 75 & 85 & & 23.0 & 22.8 & 23.0 & $\mathrm{C}$ & 1.14 & 1.07 & & & 75 & 85 & & 143.1 & 141.7 & 125.6 & $\mathrm{C}$ & 1.11 & 1.03 \\
\hline & & & 120 & & 32.4 & 28.7 & 23.0 & $\mathrm{C}$ & 1.04 & 1.02 & & & & 120 & & 202.0 & 178.5 & 125.6 & $\mathrm{C}$ & 1.06 & 1.02 \\
\hline & & & 50 & & 23.2 & 23.2 & 29.5 & $\mathrm{~T}$ & 1.00 & 0.99 & & & & 50 & & 130.0 & 130.0 & 154.5 & $\mathrm{~T}$ & 1.05 & 1.02 \\
\hline & & 50 & 85 & & 39.4 & 34.6 & 37.6 & $\mathrm{~T}$ & 0.97 & 1.02 & & & 50 & 85 & & 221.0 & 192.4 & 172.0 & $\mathrm{C}$ & 0.93 & 0.96 \\
\hline & & & 120 & & 55.6 & 42.7 & 38.7 & $\mathrm{C}$ & 0.88 & 0.98 & & & & 120 & & 312.0 & 239.4 & 170.3 & $\mathrm{C}$ & 0.86 & 0.91 \\
\hline & 20 & & 50 & 200.4 & 23.2 & 23.2 & 31.3 & $\mathrm{~T}$ & 0.99 & 0.99 & 400 & 25 & & 50 & 661.0 & 130.0 & 130.0 & 160.0 & $\mathrm{~T}$ & 1.00 & 0.98 \\
\hline & & 75 & 85 & & 39.4 & 39.2 & 45.3 & $\mathrm{~T}$ & 1.05 & 1.02 & & & 75 & 85 & & 221.0 & 219.6 & 226.7 & $\mathrm{C}$ & 1.08 & 1.03 \\
\hline & & & 120 & & 55.6 & 50.1 & 50.3 & $\mathrm{C}$ & 1.00 & 1.01 & & & & 120 & & 312.0 & 278.1 & 226.7 & C & 0.96 & 0.96 \\
\hline & & & 50 & & 29.8 & 29.8 & 39.9 & $\mathrm{~T}$ & 0.97 & 0.97 & & & & 50 & & 214.8 & 214.8 & 269.2 & $\mathrm{~T}$ & 0.94 & 0.94 \\
\hline & & 50 & 85 & & 50.7 & 45.2 & 51.2 & $\mathrm{~T}$ & 0.91 & 0.96 & & & 50 & 85 & & 365.1 & 324.2 & 355.8 & $\mathrm{~T}$ & 0.93 & 0.98 \\
\hline & 30 & & 120 & 4108 & 71.6 & 55.6 & 57.2 & $\mathrm{~T}$ & 0.87 & 0.99 & & 50 & & 120 & 2386 & 515.4 & 402.4 & 386.8 & $\mathrm{~T}$ & 0.87 & 0.97 \\
\hline & 30 & & 50 & 410.8 & 29.8 & 29.8 & 42.6 & $\mathrm{~T}$ & 0.96 & 0.98 & & 50 & & 50 & 2386 & 214.8 & 214.8 & 311.4 & $\mathrm{~T}$ & 1.01 & 1.03 \\
\hline & & 75 & 85 & & 50.7 & 50.5 & 61.4 & $\mathrm{~T}$ & 0.99 & 0.98 & & & 75 & 85 & & 365.1 & 363.6 & 429.4 & $\mathrm{~T}$ & 1.01 & 0.99 \\
\hline & & & 120 & & 71.6 & 65.6 & 72.6 & $\mathrm{~T}$ & 0.98 & 1.01 & & & & 120 & & 515.4 & 468.6 & 507.3 & $\mathrm{~T}$ & 1.01 & 1.03 \\
\hline & & & 50 & & 45.6 & 45.6 & 52.3 & $\mathrm{C}$ & 1.08 & 1.04 & & & & 50 & & 134.5 & 134.5 & 140.1 & C & 1.15 & 1.08 \\
\hline & & 50 & 85 & & 77.5 & 67.1 & 54.9 & $\mathrm{C}$ & 0.93 & 0.94 & & & 50 & 85 & & 228.7 & 196.9 & 140.4 & $\mathrm{C}$ & 1.03 & 1.00 \\
\hline & & & 120 & & 109.4 & 83.4 & 54.9 & $\mathrm{C}$ & 0.90 & 0.93 & & & & 120 & & 322.9 & 245.7 & 140.4 & $\mathrm{C}$ & 1.15 & 1.07 \\
\hline 300 & 15 & & 50 & 181.3 & 45.6 & 45.6 & 54.6 & $\mathrm{~T}$ & 1.02 & 1.00 & 500 & 15 & & 50 & 302.8 & 134.5 & 135.5 & 152.3 & $\mathrm{~T}$ & 1.11 & 1.06 \\
\hline & & 75 & 85 & & 77.5 & 76.8 & 78.6 & $\mathrm{C}$ & 1.15 & 1.09 & & & 75 & 85 & & 228.7 & 226.1 & 189.8 & $\mathrm{C}$ & 1.16 & 1.07 \\
\hline & & & 120 & & 109.4 & 97.0 & 78.6 & $\mathrm{C}$ & 1.06 & 1.03 & & & & 120 & & 322.9 & 284.4 & 189.8 & $\mathrm{C}$ & 1.16 & 1.08 \\
\hline & & & 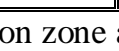 & & ure & e cor & ssio & & & & & & & & & & & Ave & age & 1.00 & 1.00 \\
\hline & & & & & & & & & & & & & & & & & & $\overline{\mathrm{CoV}}$ & & 7.93 & 3.92 \\
\hline
\end{tabular}

